\title{
Panel 3: Genomics, precision medicine and targeted therapies
}

\section{Santos-Cortez, R.L.P.}

2020-03

Santos-Cortez , R L P , Bhutta , M F , Earl , J P , Hafrén , L , Jennings , M , Mell , J C , Pichichero, M E , Ryan , A F , Tateossian, H \& Ehrlich , G D 2020 , ' Panel 3: Genomics, precision medicine and targeted therapies ' , International Journal of Pediatric Otorhinolaryngology , vol. 130 , 109835 . https://doi.org/10.1016/j.ijporl.2019.109835

http://hdl.handle.net/10138/329316

https://doi.org/10.1016/j.ijporl.2019.109835

cc_by_nc_nd

acceptedVersion

Downloaded from Helda, University of Helsinki institutional repository.

This is an electronic reprint of the original article.

This reprint may differ from the original in pagination and typographic detail.

Please cite the original version. 


\section{Panel 3: Genomics, Precision Medicine and Targeted Therapies}

3 Authors: Regie Lyn P. Santos-Cortez ${ }^{\mathrm{a}}$, Mahmood F. Bhutta ${ }^{\mathrm{b}}$, Joshua P. Earl ${ }^{\mathrm{c}}$, Lena Hafrén ${ }^{\mathrm{d}}$,

4 Michael Jennings ${ }^{\mathrm{e}}$, Joshua C. Mell ${ }^{\mathrm{c}}$, Michael E. Pichichero ${ }^{\mathrm{f}}$, Allen F. Ryan ${ }^{\mathrm{g}}$, Hilda Tateossian ${ }^{\mathrm{h}}$,

5 Garth D. Ehrlich

6

7 Affiliations:

8 a Department of Otolaryngology, School of Medicine, University of Colorado Anschutz Medical

9 Campus, 12700 E. $19^{\text {th }}$ Ave., Aurora, CO 80045, USA

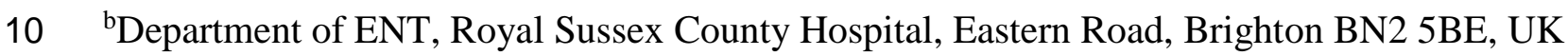

$11{ }^{\mathrm{c}}$ Center for Genomic Sciences, Institute for Molecular Medicine and Infectious Disease;

12 Department of Microbiology and Immunology; Drexel University College of Medicine, 245 N.

$1315^{\text {th }}$ St., Philadelphia, PA 19102, USA

14 department of Otorhinolaryngology, Head \& Neck Surgery, University of Helsinki and

15 Helsinki University Hospital, Helsinki, Tukholmankatu 8A, 00290 Helsinki, Finland

16 Institute for Glycomics, Gold Coast campus, Griffith University, QLD 4222, Australia

$17{ }^{\mathrm{f}}$ Center for Infectious Diseases and Immunology, Rochester General Hospital Research Institute,

181425 Portland Ave., Rochester, NY 14621, USA

19 'Department of Surgery/Otolaryngology, University of California San Diego, 9500 Gilman Dr.,

20 La Jolla, CA 92093, USA

$21{ }^{\mathrm{h}}$ Mammalian Genetics Unit, MRC Harwell Institute, Harwell, Oxford, Didcot OX11 0RD, UK

22

23 
2 Corresponding Authors:

3 Garth D. Ehrlich, Center for Genomic Sciences, Institute for Molecular Medicine and Infectious

4 Disease; Department of Microbiology and Immunology; Drexel University College of Medicine,

5245 N. $15^{\text {th }}$ St., Philadelphia, PA 19102, USA; email: ge33@drexel.edu

6 Regie Lyn P. Santos-Cortez, Department of Otolaryngology, School of Medicine, University of

7 Colorado Anschutz Medical Campus, 12700 E. 19 ${ }^{\text {th }}$ Ave. MS:8606, Aurora, CO 80045, USA;

8 email: regie.santos-cortez@cuanschutz.edu

9

10

11

12 


\section{Abstract}

2 Objective: To review the most recent advances in human and bacterial genomics as applied to

3 pathogenesis and clinical management of otitis media.

4 Data Sources: PubMed articles published since the last meeting in June 2015 up to June 2019.

5 Review Methods: A panel of experts in human and bacterial genomics of otitis media was

6 formed. Each panel member reviewed the literature in their respective fields and wrote draft

7 reviews. The reviews were shared with all panel members, and a merged draft was created. The

8 panel met at the 20th International Symposium on Recent Advances in Otitis Media in June

9 2019, discussed the review and refined the content. A final draft was made, circulated, and

10 approved by the panel members.

11 Conclusion: Trans-disciplinary approaches applying pan-omic technologies to identify human

12 susceptibility to otitis media and to understand microbial population dynamics, patho-adaptation

13 and virulence mechanisms are crucial to the development of novel, personalized therapeutics and

14 prevention strategies for otitis media.

15 Implications for Practice: In the future otitis media prevention strategies may be augmented by

16 mucosal immunization, combination vaccines targeting multiple pathogens, and modulation of

17 the middle ear microbiome. Both treatment and vaccination may be tailored to an individual's

18 otitis media phenotype as defined by molecular profiles obtained by using rapidly developing

19 techniques in microbial and host genomics.

20

21 Keywords: otitis media, otitis-prone, microbiome, metagenomics, genome-wide association

22 study, precision medicine 


\section{Introduction}

2 Despite significant decreases in incidence and prevalence worldwide, otitis media (OM) remains

3 a very common diagnosis particularly among children and the elderly. OM continues to impose a

4 major public health burden across human populations and disproportionately affects socially and

5 disadvantaged persons, e.g. indigenous communities. Part of the reason why OM burden cannot

6 be easily eliminated is the incomplete understanding of the OM phenotype and its underlying

7 disease mechanisms.

8 Human studies of genetic predisposition to experience OM rely on the supposition that

9 the history of diagnosis of OM is accurate. Contamination of the defined susceptible population

10 by individuals who have not experienced OM complicates analysis. The extent of contamination

11 of the susceptible population by "non-susceptibles" currently cannot be known and may vary

12 widely. Precision in diagnosis varies over time for several reasons. The definitions of OM, acute

13 (A)OM and OM with effusion (OME) have changed as recently as 2004 following guidelines

14 from the American Academy of Pediatrics (AAP), then revised again by the AAP in 2013 [1-2].

15 Moreover, the clinical diagnosis is challenging especially in young children and as such

16 estimates of misdiagnosis can range as high as 50\% [3-9]. Clinicians that are specifically trained

17 and tested on their accuracy of diagnosis (proven by tympanocentesis after clinical diagnosis) are

18 termed "validated otoscopists" but they represent $<1 \%$ of those making OM diagnoses.

19 Tympanocentesis-proven OM is the gold standard of diagnosis but very few clinicians practice

20 this procedure, mostly due to the required skill set for performing tympanocentesis. From a

21 prospective, longitudinal study of children from Rochester, NY, 27\% of the children studied met

22 the criteria of otitis-prone (3 AOM infections within 6 months or 4 AOM infections within a

23 year) by age 30 months old if children were diagnosed with AOM by primary care clinicians 
1 [10]. In contrast, if the diagnosis was made by validated otoscopists, $14 \%$ met the otitis-prone

2 definition, while if diagnosis was made by tympanocentesis, $6 \%$ met the otitis-prone definition

3 [10]. That study gives a perspective on the magnitude of the problem of misclassification of OM.

4 Note that such misclassification may occur not only for AOM but also for chronic (C)OM with

5 effusion especially if with an intact eardrum.

6 At this time of rapid development in molecular -omic technologies, OM clinicians and

7 scientists must take advantage of these advances to improve understanding and classification of

8 the OM phenotype by integrating knowledge of host, pathogen, and microbiome interactions

9 with overall health status and to enable improvements in OM management and reduction of OM

10 incidence, with the ultimate goal of personalizing treatment and prevention. Here we review the

11 most recent discoveries in human and microbial genomics as applied to OM pathogenesis and 12 precision medicine.

\section{2. Methods}

15 Published literature in PubMed was searched since the last symposium. Search terms included

16 "otitis media", "acute otitis media", "recurrent acute otitis media", "chronic otitis media",

17 "chronic otitis media with effusion", "gene", "genome-wide association studies", "GWAS",

18 "loci", "mouse model", "animal model", "microbiome", "metagenomics", "epigenetic",

19 "personalized medicine", "precision medicine". The search included all published literature with

20 available English abstracts. No further exclusion or selection criteria were employed. Additional

21 inputs were also taken from each panel member on their specific areas of OM expertise. 


\section{$1 \quad$ 3. Discussion}

\section{$2 \quad 3.1 \quad$ Discovery of OM Susceptibility and Protective Loci in Humans}

4 Twenty-one significant loci have been identified in five genome-wide association studies

5 (GWAS; Table 1). Of these variants, 15 were identified in a 23 andMe study that included

$6>120,000$ European-descent individuals [12,13]. Additionally four of the loci were either coding

7 variants or in linkage disequilibrium (LD) with coding variants (Table 1): (A) The PLG

8 c.112A>G (p. Lys38Glu; rs73015965) variant is pathogenic for autosomal recessive type I

9 plasminogen deficiency that includes COM as a clinical manifestation [16]. Plg-knockout mice

10 are also known to spontaneously develop COM [17]. In the GWAS, the heterozygous genotype

11 for the rs73015965 is a risk factor for childhood ear infections (OR=1.43; 95\%CI: 1.26,1.63;

$\left.12 p=3.8 \times 10^{-8}\right)[12]$. (B) A synonymous variant within $F U T 2$, c.249C $>\mathrm{T}$ (p.Tyr83=; rs681343), was

13 initially identified as a protective variant in homozygous individuals with OM but was later

14 reported as a risk allele $[12,13,18]$. The rs681343 variant is in almost complete LD with FUT2

15 c.461G>A (p.Trp154*; rs601338) [12,13,18] which has in the genome Aggregation Database

16 (gnomAD.broadinstitute.org) a minor allele frequency (MAF) 0.26-0.50 in various populations

17 except East Asians (MAF=0.002). This stop variant has been well-studied as a protective factor

18 against multiple non-OM infections [18,19]. It also results in higher plasma vitamin B12 levels

19 [20]. Conversely rs601338 increases risk for autoimmune disorders such as Behcet's, celiac and

20 inflammatory bowel diseases [18,21]. In multi-ethnic families and probands with OM, several

21 coding variants within FUT2 were identified to confer OM susceptibility [18]. This is further

22 supported by the transient expression of Fut2 in non-typeable Haemophilus influenzae (NTHi)-

23 inoculated mouse middle ears and by decreased epithelial A antigen levels due to FUT2 variants

24 [18]. (C) The intronic TBX1 rs1978060 variant is in almost complete LD with TBX1 c.1189A>C 
(p.Asn397His; rs72646967) [13]. Tbxl-knockout mice have COM that is characteristic of

2 22q11.2 deletion syndrome in humans [22,23]. In the 23andMe GWAS the TBX1 rs1978060

3 variant was identified as a risk factor for both childhood ear infections and myringotomy [12,13].

4 (D) The intronic variant $C D H R 3$ rs114947103 is in almost complete LD with $C D H R 3$

5 c.1586G>A (p.Cys529Tyr; rs6967330) [13]. Previously CDHR3 rs6967330 was implicated in a

6 GWAS for asthma, particularly for wheezing after rhinovirus infection [24-26]. On the contrary

7 for childhood ear infections, the $C D H R 3$ rs114947103 variant was identified as a protective

8 factor $\left(\mathrm{OR}=0.94 ; 95 \% \mathrm{CI}: 0.91,0.96 ; p=5.4 \times 10^{-9}\right)[12]$.

9 From these GWAS only five genes or variants were replicated in an independent OM

10 dataset (Table 1): (a) FUT2 [12,13,18]; (b) TBX1 variant rs 1978060 [12,13]; (c) ABO [12,27,28];

11 (d) intergenic variant rs10497394 on chromosome 2q31.1 which lies between genes CDCA7 and

12 SP3 [14]; and (e) a 3'UTR variant in FNDC1 [15]. ABO blood types were previously known to

13 be associated with different otitis media types, such that type $\mathrm{O}$ is protective while type A

14 increases risk for OM [27,28]. The initial GWAS for the rs10497394 and FNDC1-3'UTR

15 variants reported independent replication, indicating that they are credibly associated with OM

$16[14,15]$. Moreover FNDCl variants were positively correlated with FNDC1 expression levels but

17 negatively correlated with methylation status of FNDC1 [15]. To date, the FNDC1 variant

18 rs2932989 is the only significant epigenetic signal identified for OM in humans.

All of the five replicated GWAS loci were identified as expression quantitative trait loci

20 (eQTL) for various mucosal and epithelial tissues in the Genotype-Tissue Expression (GTEx)

21 database (gtexportal.org, accessed 21 August 2019), suggesting a regulatory function for these

22 variants (Table 2). Unfortunately middle ear mucosal epithelium is not represented in GTEx.

23 While the majority of these eQTL variants affect expression levels of genes where they lie, some 
1 of the variants have more distant effects (e.g. variant rs885932 at $6 \mathrm{p} 22.1$ is $0.87 \mathrm{Mb}$ proximal to

2 target gene IER3 at 6p21.33). Of note, four of the ten eQTL-GWAS loci affect expression of

3 multiple genes in various tissues (Table 2). The rs4329147 variant not only primarily affects

$4 \quad H L A-D R B 5$ expression but also influences the expression of six other HLA genes and four

5 additional non-HLA genes, including complement gene $C 4 A$ (Table 2). While the initial

6 23andMe study identified the rs4329147 variant as the most significant locus among HLA alleles

7 (Table 1), a follow-up study on the same dataset demonstrated that this association is lost when

8 conditioning for the $H L A-D R B 1$ Gln96 allele is performed, implying that the association is

9 largely driven by the amino acid variant within $H L A-D R B 1[12,13]$.

10 When the genes associated with eQTL variants are analyzed in NetworkAnalyst [29],

11 significant pathways based on protein-protein interactions included the following: protein

12 binding, MHC class II receptor activity, antigen processing and presentation, endocytosis,

13 immune response, regulation of binding, regulation of TGF- $\beta$ receptor signaling, pattern

14 specification process, endoderm development, collagen and chromatin binding, chromatin

15 remodeling, and regulation of Ras GTPase activity and of catabolic process. These results

16 provide a glimpse of which pathways are important in the development of OM based on the

17 genes that have been identified so far by GWAS.

\subsection{Host Genomics in Animal Models for OM}

20 Several animal models of OM have been developed over the years (Table 3). The chinchilla,

21 Chinchilla lanigera, has long been used as model of OM because it recapitulates the human

22 condition very faithfully with respect to pathogen detection [30] and the severity of disease

23 induced by different strains of the same bacterial species [31]. Based on the demonstrated 
usefulness of this model, the ISOM community convinced the National Human Genome

2 Research Institute to conduct a chinchilla genome project which culminated in the publication of

3 a comprehensive chinchilla genomic resource [32] which is being exploited for host-pathogen

4 interactions. The mouse has also become one of the favored models for genetic studies because

5 of its lifespan, easy breeding and well-established methods for introducing genetic modifications.

6 In addition, the similarities in auditory structure between mouse and human and the close

7 evolutionary relationship of these two genomes, make the mouse a valuable model to study the

8 genetics of hearing [52], although there are also limitations in inter-species comparisons, and

9 comparison of syndromic to non-syndromic disease. In the past four years, mouse studies have

10 identified several genes and genetic pathways involved in the predisposition to OME including

11 the following examples.

FLI1 and ETS1 are transcription factors from the ETS (E26 transformation-specific)

13 family, known to be hemizygous in Jacobsen syndrome. It has been demonstrated that these

14 genes have a role in the development of the nose, middle ear cavity and ossicles. The Fli1 ${ }^{+/-}$and

$15 \mathrm{Etsl}^{+/-} / \mathrm{Flil}^{+/-}$mice exhibit hearing impairment associated with COM, inflamed middle ear

16 epithelium, abnormally small middle ear cavity, fusion of ossicles to the middle ear wall, and

17 deformed stapes [41].

18 Mouse mutants called asj (ages with stiffened joints), which have a point mutation in the

19 Enppl gene, were also reported to have conductive hearing loss. At six weeks of age, the

20 mutants exhibited effusion in the middle ear, thickened middle ear epithelium, impaired

21 Eustachian tube function due to epithelia proliferation, fusion of the malleus and incus, and

22 calcification of middle ear structures [39]. 
Mutations in EDA, EDAR and EDARADD genes have been described as triggering HED

2 (hypohidrotic ectodermal dysplasia). Eda- (Ectodysplasin a) and Edar- (Ectodysplasin a

3 receptor) mutant mice ( $E d a^{T a}$ and $\left.E d a r^{d l J / d l J}\right)$ were reported to develop OM, rhinitis and

4 nasopharyngitis. They also display reduced mucociliary clearance and the loss of glandular

5 secretions [53].

$6 \quad$ Studying the ENU mutant edison revealed that a point mutation in the Nisch (Nischarin)

7 gene results in the development of conductive hearing loss due to COM. Homozygous edison

8 mice spontaneously develop COM as early as three weeks of age. The mutants also demonstrate

9 mild craniofacial defects, middle ear cavities filled with fluid and lined with thickened

10 mucoperiosteum, polypoid growths into the middle ear cavity, and in the more severely affected

11 mice inflamed tympanic membranes. Furthermore, an investigation of the impact of the edison

12 mutation on pathways in which Nischarin is involved in has implicated LIMK1 and NF- $\kappa \mathrm{B}$

13 pathways in the development of COM [46].

BPIFA1 is a member of the bacterial permeability-increasing (BPI) fold containing

15 family of putative innate defense proteins and is one of the most abundant secretory proteins in

16 the upper respiratory tract. Bpifal-knockout mice do not develop spontaneous OM up to six

17 months although BPIFA1 is highly expressed in the middle ear epithelium. However, deletion of

18 Bpifal in Junbo mice, one of the first models of COM, results in significant exacerbation of the

19 phenotype including thickening of the middle ear mucosa and increased collagen deposition.

20 This finding indicates a role for BPIFA1 in mucosal protection [54].

21 Down syndrome is caused by an extra copy of some or all of the genes of human

22 chromosome 21 (Hsa21). The orthologs to the genes from Hsa21 are spread among three regions

23 on the mouse genome located on chromosomes 10 (Mmu10), 16 (Mmu16) and 17 (Mmu17). 
1 Ongoing study at the MRC Harwell Institute on the phenotype of the DpTyb mice, which are

2 mouse models of Down syndrome, revealed that mice with full duplication of the genes from

3 Mmu16 have conductive hearing loss due to the development of middle ear inflammation. A

4 detailed study on the OM phenotype of mouse strains with full duplication of the genes from

5 Mmu10 and 17 and with duplication of smaller segments of the Dp1Tyb region will provide a

6 better understanding of the genes and genetic pathways involved in the development of OM in

7 Down syndrome.

8

\section{$9 \quad 3.3 \quad$ Advances in Microbiome Analyses}

10 Although viruses are known to play a role in OM, genomic studies on viruses in the middle ear

11 were not conducted during the study period. Thus this section concentrates on bacterial

12 genomics.

13

$14 \quad$ 3.3.1 New technologies for 16S rRNA sequencing for OM bacterial pathogens

15 Recently an improved pan-bacterial domain molecular diagnostic (MDx) that uses PCR and

16 circular consensus reads (CCS) of the entire bacterial 16S rRNA (FL16S) gene on Pacific

17 Bioscience (PacBio) $3^{\text {rd }}$-4th generation sequencers has been developed $[55,56]$. The process

18 incorporates both laboratory and informatic improvements over extant systems. Briefly, CCS

19 provides for multiple polymerase-driven sequencing-read-passes of a single DNA molecule,

20 where each 'pass' of the molecule corresponds to the sequence of sense or antisense strand. Each

21 pass is used towards the creation of a consensus sequence, generating ultra-high-quality

22 sequences (as individual PacBio errors are not sequence context dependent) providing for

23 unambiguous species calls when paired with the companion informatics system, called

24 MCSMRT. This pipeline for quantitatively and specifically profiling microbiota includes a 
1 custom full-length 16S gene database. Beginning with PCR of the entire 16S rRNA gene the

2 resultant amplimers are then sequenced on a PacBio sequencer. CCS read sequences are

3 calculated based on average $>15$ passes resulting in expected error rates of $\leq 1$ incorrectly called

4 base per FL16S gene read in over half the data. MCSMRT has extended and improved upon

5 previous applications of PacBio 16S sequencing [57-64], including: (A) incorporation of

6 stringent filters eliminating sources of sequencing artifacts, effectively eliminating inflated

7 operational taxonomic unit (OTU) counts, a pervasive problem in short read microbiome

8 protocols [65]; (B) assignment of taxonomy and confidence values to OTUs using the custom-

9 designed full-length $16 \mathrm{~S}$ database which provides a uniform Linnaean hierarchy for each read.

10 The combination of these factors resulted in a pan-domain MDx that is highly quantitative, even

11 for complex microbiota. Analysis of the Critical Assessment of Metagenome Interpretation

12 (CAMI) community (>250 species) demonstrated its ability to identify and determine

13 abundances of hundreds of species over $>3$ logs of variance (Fig. 1) [55].

14 Two recent innovations that improve the accuracy and ability to discriminate among

15 closely related species and strains have been added to MCSMRT: (A) upon ascertaining that

$16 \sim 5 \%$ of the $16 \mathrm{~S}$ amplimers were hybrids of mismatched, closely related single-stranded DNAs

17 (from closely related species, or different intragenomic copies), the ability to produce CCS reads

18 derived from each strand was added as an option; and (B) a new, more accurate algorithm for

19 calling sequences based on graph deconvolution, as opposed to a multiple sequence alignment

20 strategy was added. This latter technique builds on the algorithm introduced in 2002 based on a

21 directed acyclic graph [66]. Using these algorithmic improvements, the quality of even the

22 unfiltered CCS reads substantially improved from an average of 8.0 to 2.2 expected errors, and

23 resulting in improved post-filter yields, improving from $86 \%$ to $98 \%$ recovery. 
Informatic analyses have seen additional recent advances. Significant challenges in

2 assessing differential abundance of microbial taxa exist due to unbalanced sampling, and

3 artifacts from both PCR and sequencing. Traditional methods (such as rarefaction) have been

4 shown to be untenable for accurate statistical comparisons within microbiome data [67]. New

5 analysis software has been designed that properly normalize OTU counts across samples using

6 Gaussian mixture models, and have been added to popular R microbiome analysis library

7 frameworks, such as phyloseq [68-70]. OTU representation of the microbiome (where sequences

8 are usually clustered together based on an identity threshold of 97\%) have also been recently

9 challenged as inadequate to properly account for all microbial diversity within a sample [71].

10 Recent programmatic packages now exist that can be applied after OTU analysis (such as that

11 done in MCSMRT) to further examine diversity based on single nucleotide variants within the

12 OTU sequences [72,73].

13 Another recent advancement with strong implications for a FL16S microbiome pipeline

14 is the development of a kit by the company Shoreline Biome (Farmington, CT, USA), created

15 specifically to go from sample to prepared PacBio sequencing libraries in a series of predefined

16 laboratory steps. The advantages of this pipeline are a pre-designed system for cell lysis, PCR

17 amplification of FL16S, and sample pooling of up to 100 samples per run. This kit streamlines

18 the process resulting in a significant reduction of man hours required for sample library

19 preparation (estimated reduction from 16-25 hours to $\sim 2$ hours). Taken together, these exciting

20 new developments in microbial sequencing technologies are expected to have a major impact in

21 scientific discoveries and novel clinical applications in otopathogen detection and

22 characterization. 
2 The above-mentioned microbiome MDx was used to characterize 20 bilateral COM with

3 effusion cases to investigate their polymicrobial nature (Fig. 2). Right and left middle ears

4 typically had similar communities though exceptions existed (patients 12, 27 and 32 in Fig. 2).

5 The major otopathogens causing AOM are NTHi, Streptococcus pneumoniae (Spn) and

6 Moraxella catarrhalis (Mcat). These OM pathogens were prevalent among the chronic OM

7 patients (6 Mcat, $4 \mathrm{NTHi}, 3 \mathrm{Spn}$ : $55 \%$ of cases with $1+$ ), but under-recognized species were more

8 prevalent: 40\% Alloiococcus otitis, 40\% Staphylococcus auricularis, 30\% Turicella otitidis, 30\%

9 Staphylococcus caprae, and 10\% Aggregatibacter aphrophilus [74]. The extremely high

10 abundances of these "atypical" species in all cases suggest that they are likely OM etiological

11 agents, and not simply contaminants from the external auditory canal.

\section{$13 \quad 3.4 \quad$ Bacterial population genomics to dissect otopathogen-specific virulence genes and}

\section{4 mechanisms}

15 Whole-genome shotgun (WGS) sequencing of clinical bacterial isolates is rapidly

16 revolutionizing clinical microbiology, not only by increasing the throughput and resolution of

17 strain typing but also enabling detection of associations between bacterial genetic variation and

18 clinical pathogenesis phenotypes [75-78]. Bacterial supra-GWAS (SGWAS) presents special

19 challenges [79-81], including inadequate or biased sampling (especially of carriage isolates),

20 limited clinical metadata availability, strong phylogenetic substructure and genomic (gene

21 content) diversity among strains, and a lack of consensus among varied bioinformatic analysis

22 pipelines. Nevertheless, increasingly large datasets and sophisticated tools [82-84] are now

23 detecting signatures of in-host bacterial evolution by identifying recurrent and parallel genomic 
1 changes arising over the course of infections or between healthy and diseased states. Isolating

2 these in situ genomic signatures of bacterial transitions to pathogenesis ("pathoadaptations") in

3 turn informs our understanding of pathogenic mechanisms in the human host [85-87].

4 Combining comparative genomic analysis with transcriptomic and other -omic technologies to

5 investigate in vivo and in situ host-pathogen interactions will allow the integration of clinical and

6 molecular mechanistic studies of bacterial pathogenesis.

7 This emerging discipline of "genomic epidemiology" has been broadly applied to

8 bacterial pathogens, but has only begun to be used to dissect OM pathogenesis. The three main

9 bacterial otopathogens NTHi, Spn and Mcat are all amenable to large-scale SGWAS [88-105], a

10 technique that takes into account that the majority of bacterial species' genes are not found in all

11 strains of the species, but are rather distributed among the many strains. Indeed, all three

12 organisms have many publicly available WGS assemblies including complete reference genomes

13 at NCBI (as of June 2019: $\mathrm{Sp}=10,462$ assemblies, NTHi=735, Mcat=114), and additional

14 genomes are continuing to accrue from diverse sources and disease states. In contrast to studies

15 of environmental opportunistic pathogens that typically colonize subjects as single clones that

16 subsequently evolve and diversify (e.g. Pseudomonas and Burkholderia cenocepacea in cystic

17 fibrosis infections) [106,107], population-level genomic studies in human-restricted normal

18 commensals — like the three main otopathogens — are complicated by the high diversity and

19 polyclonality of these species when isolated from diverse health and disease states. Below, we

20 summarize recent WGS surveys and association studies from NTHi. Although none have yet

21 been specifically focused on OM diseases, the findings suggest that our understanding of OM

22 pathogenesis could be greatly expanded by GWAS and other -omics approaches. 
H. influenzae became an early genomic model system when the lab strain Rd became the

2 first cellular organism to have its complete genome sequenced in 1995 [108], and the pace of

3 WGS has continued to increase, with 735 assemblies publically available at NCBI (as of June 7,

4 2019) and >1,000 more expected in short order. Early and continuing comparative analysis of

5 NTHi genomes were among the first to recognize the immense diversity in genic content seen in

6 many bacterial species [88,89,99,100]. More recently, SGWAS studies identified gene

7 presence/absence differences strongly associated with strains isolated from carriage or disease

8 [98], and follow-up studies identified a novel multi-gene family associated with virulence, the

9 vSLR genes, one of which was shown to increase survival in macrophages ( $m s f 1)$ and also

10 enhancing the ability of OM that increases the severity of disease in the chinchilla model of OM

11 [102]. Recent studies of NTHi in chronic obstructive pulmonary disease (COPD) have revealed

12 recurrent genomic changes accumulating over time in different patients, particularly at phase

13 variable genes encoding in lipooligosaccharide synthesis enzymes and outer membrane proteins

$14[103,104]$. This also identified recurrent loss-of-function mutations in the bifunctional

15 ompPl/fadL gene as a specific NTHi patho-adaptation to the COPD lung, and also showed that

16 this is a likely evolutionary trade-off between ompPl mutants' losing their ability to adhere and

17 invade airway epithelial cells, but gaining resistance to arachidonic acid, an abundant

18 inflammatory mediator in the COPD lung [103]. Similar work with a small number of strains in

19 pediatric pulmonary infections found limited evidence for parallel evolution but nasal-lung

20 isolate pairs also showed convergent transcriptional signatures by in vitro RNA-seq [105].

21 Additional SGWAS has been been performed for population-level and epidemiological analysis

22 of the NTHi, including new invasive isolates from the US [106]and Portugal [107], as well as a

23 detailed analysis of 265 strains collected in the UK that identified lineage-specific associations 
1 with pneumococcus and shifts in NTHi population structure in carriage upon introduction of the

2 PCV13 vaccine [108]. These results all show the power of comparative analysis of bacterial

3 genomes.

4 Excitingly, recent technical and informatic advances in metagenomic sequencing together

5 with novel cultural protocols provide for the systematic capture of much deeper and more

6 complete views of highly complex polyclonal and polymicrobial populations while providing for

7 the near complete genome sequencing and assembly of both very rare strains and strains that are

8 recalcitrant to culture. These advances provide for deep, strain-traceable, metagenomic/WGS

9 characterization of polyclonal populations in situ - when combined with a multipartite specimen

10 collection approach to provide comprehensive strain-, gene-, and pan(supra)genome-based

11 analyses of any clinical sample -- and particularly useful for following over time the evolution of

12 clonal lineages and inter-strain population dynamics. A comprehensive approach to

13 understanding these issues with respect to the evolution of otopathogenesis at the population-

14 level, particularly with regard to horizontal gene transfer includes: (A) WGS of large numbers of

15 individual isolates recovered simultaneously from middle ear effusions and the nasopharynx; (B)

16 the metagenomic, and ligation-proximity-metagenomic sequencing of all recovered colonies

17 from each specimen that have been pooled to form a 'gimish' $[109,110]$ to construct

18 genomes/clonal lineages of lower prevalence strains; (C) metagenomic sequencing of uncultured

19 clinical specimen DNA that has been selected using a species-specific capture reagent [98] to

20 provide coverage for unculturable strains; and (D) the use of gel microdroplets (GMD) to

21 encapsulate single cells for the production of sequestered clonal microcolonies grown in co-

22 culture which can provide sufficient genomic DNA for whole genome amplification (MDA) and

23 subsequent genomic assemblies [111,112]. Selection of individual GMD microcolonies for 
sequencing is achieved via FACS using labeled probes made from metagenomically identified

2 genes that are not present in the strains which underwent WGS.

$4 \quad 3.5 \quad$ Epigenetic regulation in bacterial otopathogens

6 Many bacterial pathogens that are adapted to the human host display random, high-frequency

7 on/off switching of gene expression, called phase variation [113]. This gene regulation strategy

8 generates a diverse bacterial population that provides many possible solutions to the challenges

9 posed by distinct immunological memories. In most cases, the phase variably expressed genes

10 encode surface exposed antigens such as outer membrane proteins and variable oligosaccharide

11 structures. Two of the major otopathogens H. influenzae [114] and Mcat [115] are archetypal

12 examples of bacterial pathogens that exhibit phase variable gene expression and have many

13 phase variable genes.

In 2005 a new type of epigenetic regulation system called a phase variable regulon

15 (phasevarion), was described in H. influenzae [116]. Phasevarions are controlled by DNA

16 methyltransferases that randomly switch on and off, leading to changes in DNA methylation at

17 thousands of sites in the genome and consequent changes in global gene expression [117]. Both

18 H. influenzae [118] and Mcat [119] contain multiple phasevarion systems that control virulence

19 and immune evasion. In the case of $H$. influenzae, the impact of phasevarion switching in OM

20 has been confirmed in the chinchilla model [118]. Spn also has a DNA methyltransferase that

21 randomly switches between six different DNA methylation patterns by recombination that

22 regulates virulence in a murine model system and immune evasion [120].

24 pathogenesis of all major bacterial otopathogens causing OM [118-120]. Further studies on 
1 human clinical samples are required to assess the impact of these systems in regulating the

2 adaptation of the pathogen to the human host in distinct phases of disease and distinct host

3 niches, e.g. to address the question of a potential role for phasevarion-mediated regulation of the

4 transition from nasopharyngeal colonization to active OM infection.

5 The epigenetic regulation of phasevarions is mediated by changes in methylation at

6 thousands of sites in the genome. The vast majority of these changes are neutral with respect to

7 impact on gene expression. Thus, it is not possible at this time to conduct in silico prediction of

8 which genes are subject to expression changes upon phasevarion switching. The inability to

9 predict which genes will be subject to phasevarion regulation presents particular problems for

10 genomics-based vaccine development [121] for these pathogens. Detailed studies of

11 phasevarion-mediated gene expression are required in all three common AOM pathogens to

12 define the repertoire of stably expressed immunological targets.

\section{$14 \quad 3.6 \quad$ Precision Medicine for $\mathrm{OM}$}

15 Precision Medicine (PM), also called personalized medicine, is designed to treat the right patient,

16 at the correct time, with the right treatment strategy. This takes into consideration the patients'

17 genetic and environmental factors, including the molecular basis of disease. This strategy has

18 been implemented in cancer treatment for some time [122-125]. Studies on primary immune

19 deficiency have revealed several hundred genetic defects associated with various disorders,

20 helped understand immunobiology and resulted in targeted new therapies [125]. For example,

21 cystic fibrosis is a monogenic disease, but more than 2000 different mutations in the CFTR gene

22 have been reported. Targeted therapies for some of these mutations, e.g. for carriers of the CFTR

23 p.Phe508del variant, are already on the market [126]. 
Application of PM in infectious diseases is much more complex than in many other

2 medical fields and, combined with the lack of new efficacious antibiotics to deal with established

3 bacterial resistance to traditional antibiotics [127-130], makes for a very challenging

4 environment for the adoption of PM. For OM, the recognition that the expression of particular

5 allelic forms of the gel-forming mucins and aquaporins are specifically linked to pediatric

6 hearing loss [131] provides the potential for targeted therapeutic interventions. Similarly,the

7 recent identification of specific host microRNAs that are associated with OM [132] (mir-223)

8 and the hyperplastic response associated with COME [133] (mir-146) provide high value targets

9 for future interventional strategies Treatment strategies for PM in infectious diseases include

10 pathogen-targeted antibiotic treatment, adjuvant therapy to antibiotics, precision antimicrobial

11 therapies, and subclassification of patient groups according to intrinsic and extrinsic factors.

12 Bacterial culture and antimicrobial sensitivity tests are available but are slow to perform

13 and therefore microbial WGS to find resistant strains is evolving [130,134]. WGS can be used to

14 select an appropriate and efficacious medication, reducing side effects and excluding toxic drugs.

15 PM based on the bacterial strain is possible in OM with suppuration from tympanic membrane

16 perforation or tympanostomy tube discharge.

17 PM in infectious diseases also includes developing non-antibiotic strategies. Precision

18 antimicrobial treatment can target certain virulence factors in pathogens, whether a gene, a

19 cellular process, or a specific microbe. These strategies also leave the rest of the human

20 microbiota intact. An unbalanced microbiota is associated with a wide range of disorders, from

21 autoimmune to psychiatric diseases. Precision antibiotic treatments include lysins, nucleic acid-

22 based systems, synthetic peptides, and mannosides. One strategy in OM would be to identify 
1 genes that favor colonization of OM pathogens in the middle ear and to develop small

2 antagonists against molecules produced by bacteria $[127,128,135]$.

3 The term -omics comprises genomics, transcriptomics, proteomics, metabolomics, and

4 microbiomes, while translational -omics refers to clinical use of multi-omic data to treat disease

5 in a precise way. It enables the definition of different endotypes of a phenotype or trait. In a

6 Cochrane review of antibiotic treatment in OM, an example of an endotype that benefits most

7 from antibiotic treatment is defined as "children under two years of age with bilateral AOM, or

8 with both AOM and otorrhea" [136]. Such endotypes are used to identify patients who will

9 benefit from different treatment strategies with fewer side effects $[127,137]$.

\section{$11 \quad 3.7 \quad$ OM Therapeutics}

12 Understandably translation of -omics findings to therapeutic use takes a long time. Recent

13 studies on OM therapeutics have focused on steroids and antibiotics, which are not-omics-

14 guided and mostly with negative results. Francis et al. (2018) performed a randomized trial of

15 oral steroids for treatment of hearing loss in OM, and found no effect [138]. Ranakusuma et al.

16 (2018) reviewed studies of oral corticosteroids for AOM, and found no evidence of effectiveness

17 in reducing duration of symptoms [139]. Lewnard et al. (2018) found that long-term amoxicillin

18 treatment did not increase the carriage of resistant Spn strains [1140]. Ruohola et al. (2018)

19 noted that immediate amoxicillin treatment for AOM did not enhance clearance of later middle

20 ear effusion [141]. Hoberman et al. (2016) found that a shortened antibiotic regimen was not as

21 effective as a full course for the resolution of OM [142]. Te Molder et al. (2016) found that

22 antibiotic treatment for a first OM episode does not affect the probability of future recurrences

23 [143]. While these studies were negative, two other studies that had positive findings showed 
1 that for children less than two years old, immediate amoxicillin was the most cost-effective

2 treatment for AOM [1144], while immediate amoxicillin treatment was modestly more effective

3 in treating OM than delayed antibiotics [145]. Outside of steroids and antibiotics, only one study

4 by Kondura et al. (2016) found that circumin reduced inflammation in an animal model of OM

5 [38].

$6 \quad$ Regarding delivery of drugs to the middle ear, Yang et al. (2016) found that delivery of

7 ciprofloxacin and penetrants in a hydrogel to the external surface of the intact tympanic

8 membrane resulted in delivery of therapeutic amounts of drug to the middle ear [146]. Kurabi et

9 al. (2017) discovered rare peptides that support active transport of large particles across the intact

10 eardrum, and enhanced transport by lengthening the peptides $[147,148]$. They also found that

11 the peptides can transit the intact human tympanic membrane [149].

\section{$13 \quad 3.8 \quad$ Vaccination for OM towards PM}

\section{$14 \quad$ 3.8.1. Pneumococcal vaccination}

15 At onset of AOM, Spn (58\%) was the predominant organism in the nasopharynx followed by

16 Mcat (55.1\%) and then $H$. influenzae (38.2\%) [150], which shows low prediction value of

17 nasopharyngeal cultures to determine the etiology of middle ear bacterial pathogens and the

18 importance of collection of middle ear fluid to identify vaccines for AOM prevention. The only

19 current licensed vaccines targeting Spn are pneumococcal conjugate vaccines (PCVs). These

20 vaccines contain 10 (PCV10) or 13 (PCV13) polysaccharide Spn serotypes conjugated to a

21 protein carrier. PCVs are effective in reducing AOM caused by the serotypes contained within

22 the vaccines [151-154]. In addition, administration of PCVs during infancy may reduce the risk

23 of recurrent AOM and progression to more complex disease caused by non-vaccine serotypes 
$1 \quad[155,156]$. However, increases in both nasopharyngeal carriage and diseases caused by non-

2 vaccine Spn capsule types are on the rise [157]. This has resulted in vaccine companies

3 developing newer PCVs such as PCV15 (Merck) [158-160] and PCV20 (Pfizer). PCV15 contains

4 the same 13 serotypes as in PCV13 plus 22F and 33F. PCV20 contains same serotypes as in

5 PCV15 plus 8, 10A, 11A, 12F and 15B/C. Both PCV15 and PCV20 are in Phase 3 clinical

6 studies in adults.

7 Although these newer PCVs will help to reduce the incidence of diseases caused by the

8 additional vaccine serotypes, history tells us that non-vaccine serotype replacements will occur

9 over time. Hence, there is a need to develop non-serotype dependent pneumococcal vaccines.

10 Efforts have been made formulating pneumococcal protein-based vaccines either alone or in

11 combination with PCVs $[160,161]$. However, none of these vaccines moved to Phase 3 clinical

12 trials because they failed to reduce nasopharyngeal colonization similar to PCVs and the indirect

13 herd immunity effect of PCVs is sought for overall public health benefit. Another approach

14 being tested is a whole cell vaccine (WCV) that generates both antibody and Th1/Th17 cellular

15 immunity thereby offering the potential to prevent Spn carriage [162,163]. A genetically

16 engineered unencapsulated killed strain of Spn that elicits IL-17A production is in clinical trials

$17[164,165]$. Additional preclinical WCVs using different engineered strains and different routes of

18 immunization (intraperitoneal or intranasal) are being studied [166,167].

\section{3.8.2. Vaccination against $H$. influenzae}

21 The only licensed vaccine is the $H$. influenzae serotype b (PRP) polysaccharide conjugate

22 vaccine. This vaccine is not effective against other $H$. influenzae capsule types that cause

23 invasive disease nor NTHi which, aside from being a major AOM pathogen, is a major pathogen 
causing COPD and invasive diseases in infants and young children [168-170]. PCV10 vaccine

2 contains protein D from $H$. influenzae conjugated to eight of the pneumococcal polysaccharides.

3 In a pediatric clinical trial using an earlier version of PCV10 and PCV11 where all 11

4 polysaccharides were conjugated to protein $\mathrm{D}$, a significant reduction in NTHi-caused AOM was

5 measured [171]. Subsequent clinical and observational studies using PCV10 showed marginal

6 efficacy against NTHi-caused AOM and had no impact on nasopharyngeal carriage of $H$.

7 influenzae [172,173].

8 Current strategies for new vaccines to prevent $H$. influenzae infections are being explored

9 and are focused on relatively conserved proteins expressed by the bacteria [174-176]. Two phase

101 clinical trials investigated a multi-component $H$. influenzae protein-based vaccine and a multi-

11 component combination Spn and $H$. influenzae protein-based vaccine $[177,178]$. Another Phase

121 trial investigated a multi-component combination $H$. influenzae and Mcat protein-based

13 vaccine to target subjects with acute exacerbations of COPD [179]. Oral vaccines using

14 inactivated NTHi to prevent acute exacerbations of COPD have been in clinical studies [180-

15 182]. A novel preclinical study using a transcutaneous immunization of a chimeric protein with a

16 band aid prevented OM in chinchillas [183]. Animal studies mimicking the natural human mode

17 of AOM as a result of nasal coinfection of virus and NTHi show promise in identifying vaccine

18 candidates [184]. An outer membrane vesicle of NTHi has been shown to be protective against

19 OM in a chinchilla model [185].

20

\section{$21 \quad$ 3.8.3. Vaccination for Mcat}

22 There are no licensed vaccines against Mcat. One of the major issues in developing a vaccine

23 against OM is lack of an animal model due to Mcat being a human-restricted pathogen [186]. 
1 Mouse pulmonary clearance and chinchilla nasopharyngeal colonization models have been used

2 for testing Mcat vaccine candidates. A number of protein and lipooligosaccharide candidates

3 have been studied preclinically [186,187]. Only one investigational clinical study of a vaccine

4 containing three NTHi proteins and one Mcat protein has been reported targeting acute

5 exacerbations of COPD [179].

6

7 3.8.3. Vaccination against Otopathogens within the Context of PM

8 From a PM perspective pneumococcal vaccines should be effective in the population which

9 experience the greatest disease burden, e.g. otitis-prone children. Otitis-prone children have

10 multiple dysfunctions in adaptive immunity including responses to vaccines [188-194]. In

11 particular, otitis-prone children respond with significantly lower antibody levels and lower

12 generation of memory B cells following PCV13 vaccination [188,194]. They respond to natural

13 immunization induced by nasopharyngeal colonization and AOM infections with less antibody

14 against pneumococcal proteins which are considered as vaccine candidates [192,195,196]. Otitis-

15 prone children also have diminished Th1 and Th17 immune responses [193] and generally have

16 poor response to most routine vaccination [188]. Similar to the response to pneumococcal

17 vaccines, otitis-prone children respond less well to $H$. influenzae type b vaccine [188], as well as

18 to several proteins expressed by $H$. influenzae and Mcat that are vaccine candidates

$19[195,197,198]$.

20

\section{4. Implications for Practice}

22 Despite the considerable morbidity and health care costs for OM treatment, a barrier that

23 prevents development of new vaccines and treatments for OM including those arising from 
1 knowledge brought forth by new genomic technologies is the lack of appreciation of $\mathrm{OM}$ as a

2 major public health threat, particularly by industry. Genetic diversity among OM pathogens is

3 another major challenge that must be addressed. From a public health perspective vaccines

4 targeting otopathogens would be most cost-effective if they not only reduced OM but also

5 reduced nasopharyngeal carriage to produce an indirect herd immunity effect. However, for any

6 vaccine, is total elimination of nasopharyngeal carriage risky? Might elimination of potential

7 otopathogens open a niche for other pathogenic organisms? Some scientists recommend that

8 elimination of nasopharyngeal colonization is not desirable, and rather enhancing the host

9 immunity to prevent bacteria from reaching a pathogenic threshold should be the goal [160].

10 Eliciting mucosal responses by formulating vaccines to enhance Th17 responses or by mucosal

11 immunization is a strategy under investigation. Combination vaccines targeting Spn, NTHi and

12 Mcat would be the preferred formulation to target $\mathrm{OM}$ and other diseases caused by these

13 pathogens. Modulating the microbiome by monitoring bacterial abundances not just of OM

14 pathogens but also of the commensal middle ear bacteria is another potential goal for OM

15 prevention.

16 The increasing pace of large-scale WGS of clinical bacterial isolates and novel insights

17 into bacterial population dynamics and pathogenesis offer great promise to dissect how bacteria

18 adapt during pathogenesis, pointing to the molecular mechanisms important within the human

19 host. The methods and tools are now available to gain direct insights into the specific bacterial

20 genomic variation that impacts OM. In combination with carefully collected and curated clinical

21 isolate collections, applying these analyses to bacterial otopathogens will not only improve

22 epidemiological tracking but also dissecting bacterial pathoadaptation and virulence

23 mechanisms. Increasing use of functional approaches, like transcriptome and metabolome 
1 analyses [199,1200] — applied in a comparative context—will help inform new disease

2 management strategies, identify new diagnostic biomarkers, and suggest new routes for

3 therapeutic intervention.

4 In the near future, human GWAS using next-generation sequence data will further

5 illuminate how coding and non-coding variants with a wide MAF spectrum, i.e. both common

6 and rare variants, play a role in OM susceptibility. Further studies in non-European populations

7 are also needed to elucidate OM susceptibility variants that are important in various human

8 ethnic groups. In addition there continue to be many advances in the identification of genes that

9 play a role in OM from animal studies, virtually all in the mouse. These include natural and

10 ENU-induced mutations, as well as studies of knockout and other gene-modified mice. The

11 categories that influence OM include genes related to immunity, inflammation, secretory

12 activity, morphology, and tissue growth. This diversity of OM-related pathways suggests that

13 many more such OM-related genes will be discovered in human and mouse studies, which are

14 important to understand mechanism of disease in OM and to determine pathways that may be

15 targeted for treatment and prevention. Collaboration between disciplines and across populations

16 is mandatory in the development of PM, where research and development in translational -omics

17 will be the cornerstone.

18

19 Funding: Funding for the generation and publication of this panel report was made possible in

20 part by 1 R13 DC017389-01 from the National Institute on Deafness and Other Communication

21 Disorders.

22 
1 Author Contributions: All authors contributed to writing, read and approved the final

2 manuscript.

3

4 Competing Interests: Dr. Allen F. Ryan is a Co-founder of and equity holder in Otonomy, Inc., a

5 company that develops slow-release compounds for local delivery of medications to the middle

6 and inner ear. The authors declare no competing interests.

7

8 References

9 1. Subcommittee on Management of Acute Otitis Media, Diagnosis and Management of 10 Acute Otitis Media, Pediatrics 113 (2004) 1451-1465.

11 2. A.S. Lieberthal, A.E. Carroll, T. Chonmaitree, T.G. Ganiats, A. Hoberman, M.A. Jackson, 12 M.D. Joffe, D.T. Miller, R.M. Rosenfeld, X.D. Sevilla, R.H. Schwartz, P.A. Thomas, D.E. 13 Tunkel, The diagnosis and management of acute otitis media, Pediatrics 131 (2013) e96414 e999.

15 3. M.K. Laine, P.A. Tahtinen, O. Ruuskanen, P. Huovinen, A. Ruohola, Symptoms or 16 symptom-based scores cannot predict acute otitis media at otitis-prone age, Pediatrics 125 $17 \quad$ (2010) e1154-e1161.

18 4. M.E. Pichichero, M.D. Poole, Assessing diagnostic accuracy and tympanocentesis skills in 19 the management of otitis media, Arch. Pediatr. Adolesc. Med. 155 (2001) 1137-1142.

20 5. N. Balasundaram, D. Phan, D. Mazzoni, E. Duong, A. Sweeny, C. Del Mar, G. Keijzers, 21 Acute otitis media in children presenting to the emergency department: Is it diagnosed and 22 managed appropriately? J. Paediatr. Child Health (2019). doi: 10.1111/jpc.14414. 
1 6. M.E. Pichichero, M.D. Poole, Comparison of performance by otolaryngologists,

2 pediatricians, and general practioners on an otoendoscopic diagnostic video examination,

3 Int. J. Pediatr. Otorhinolaryngol. 69 (2005) 361-366.

4 7. C.R. Paul, C.L. Gjerde, G. McIntosh, L.S. Weber, Teaching the pediatric ear exam and 5 diagnosis of Acute Otitis Media: a teaching and assessment model in three groups, BMC $6 \quad$ Med. Educ. 17 (2017) 146.

7 8. M.E. Pichichero, Diagnostic accuracy of otitis media and tympanocentesis skills 8 assessment among pediatricians, Eur. J. Clin. Microbiol. Infect. Dis. 22 (2003) 519-524.

9 9. J.M. Legros, H. Hitoto, F. Garnier, C. Dagorne, E. Parot-Schinkel, S. Fanello, Clinical 10 qualitative evaluation of the diagnosis of acute otitis media in general practice, Int. J. 11 Pediatr. Otorhinolaryngol. 72 (2008) 23-30.

12 10. M.E. Pichichero, J.R. Casey, A. Almudevar, Reducing the Frequency of Acute Otitis 13 Media by Individualized Care, Pediatr. Infect. Dis. J. 32 (2013) 473-478.

14 11. E. Einarsdottir, L. Hafrén, E. Leinonen, M.F. Bhutta, E. Kentala, J. Kere, P.S. Mattila, 15 Genome-wide association analysis reveals variants on chromosome 19 that contribute to 16 childhood risk of chronic otitis media with effusion, Sci. Rep. 6 (2016) 33240.

17 12. J.K. Pickrell, T. Berisa, J.Z. Liu, L. Ségurel, J.Y. Tung, D.A. Hinds, Detection and 18 interpretation of shared genetic influences on 42 human traits, Nat. Genet. 48 (2016) 709$19 \quad 717$.

20 13. C. Tian, B.S. Hromatka, A.K. Kiefer, N. Eriksson, S.M. Noble, J.Y. Tung, D.A. Hinds, 21 Genome-wide association and HLA region fine-mapping studies identify susceptibility loci 22 for multiple common infections, Nat. Commun. 8 (2017) 599. 
14. E.K. Allen, W.M. Chen, D.E. Weeks, F. Chen, X. Hou, J.L. Mattos, J.C. Mychaleckyj, F. Segade, M.L. Casselbrant, E.M. Mandel, R.E. Ferrell, S.S. Rich, K.A. Daly, M.M. Sale, A genome-wide association study of chronic otitis media with effusion and recurrent otitis media identified a novel susceptibility locus on chromosome 2, J. Assoc. Res. Otolaryngol. 14 (2013) 791-800.

15. G. van Ingen, J. Li, A. Goedegebure, R. Pandey, Y.R. Li, M.E. March, V.W. Jaddoe, M. Bakay, F.D. Mentch, K. Thomas, Z. Wei, X. Chang, A.G. Uitterlinden, H.A. Moll, C.M. van Duijn, F. Rivadeneira, H. Raat, R.J. Baatenburg de Jong, P.M. Sleiman, M.P. van der Schroeff, H. Hakonarson, Genome-wide association study for acute otitis media in children identifies FNDC1 as disease contributing gene, Nat. Commun. 7 (2016) 12792.

16. K. Tefs, M. Gueorguieva, J. Klammt, C.M. Allen, D. Aktas, F.Y. Anlar, S.D. Aydogdu, D. Brown, E. Ciftci, P. Contarini, C.E. Dempfle, M. Dostalek, S. Eisert, A. Gökbuget, O. Günhan, A.A. Hidayat, B. Hügle, M. Isikoglu, M. Irkec, S.K. Joss, S. Klebe, C. Kneppo, I. Kurtulus, R.P. Mehta, K. Ornek, R. Schneppenheim, S. Seregard, E. Sweeney, S. Turtschi, G. Veres, P. Zeitler, M. Ziegler, V. Schuster, Molecular and clinical spectrum of type I plasminogen deficiency: a series of 50 patients, Blood 108 (2006) 3021-3026.

17. P.O. Eriksson, J. Li, T. Ny, S. Hellström S, Spontaneous development of otitis media in plasminogen-deficient mice, Int. J. Med. Microbiol. 296 (2006) 501-509.

18. R.L.P. Santos-Cortez, C.M. Chiong, D.N. Frank, A.F. Ryan, A.P.J. Giese, T.C. Bootpetch Roberts, K.A. Daly, M.J. Steritz, W. Szeremeta, M. Pedro, H. Pine, T.K.L. Yarza, M.A. Scholes, E.G.d.V. Llanes, S. Yousaf, N. Friedman, M.L.C. Tantoco, T.M. Wine, P.J. Labra, J. Benoit, A.G. Ruiz, R.A.R. de la Cruz, C. Greenlee, A. Yousaf, J. Cardwell, R.M.A. Nonato, D.C. Ray, K.M.C. Ong, E. So, C.E. Robertson, J. Dinwiddie, S.M. Lagrana- 
Villagracia, University of Washington Center for Mendelian Genomics, S.P. Gubbels, R.S.

Shaikh, S.P. Cass, E. Einarsdottir, N.R. Lee, D.A. Schwartz, T.L.I. Gloria-Cruz, M.J.

Bamshad, I.V. Yang, J. Kere, G.T. Abes, J.D. Prager, S. Riazuddin, A.L. Chan, P.J. Yoon, D.A. Nickerson, E.M.C. Cutiongco-de la Paz, S.O. Streubel, M.R.T. Reyes-Quintos, H.A. Jenkins, P.S. Mattila, K.H. Chan, K.L. Mohlke, S.M. Leal, L. Hafrén, T. Chonmaitree, M.M. Sale, Z.M. Ahmed, FUT2 variants confer susceptibility to familial otitis media, Am. J. Hum. Genet. 103 (2018) 679-690.

19. M. Thorven, A. Grahn, K.O. Hedlund, H. Johansson, C. Wahlfrid, G. Larson, L. Svensson, A homozygous nonsense mutation (428G->A) in the human secretor (FUT2) gene provides resistance to symptomatic norovirus (GGII) infections, J. Virol. 79 (2005) 15351-15355.

20. A. Hazra, P. Kraft, J. Selhub, E.L. Giovannucci, G. Thomas, R.N. Hoover, S.J. Chanock, D.J. Hunter, Common variants of FUT2 are associated with plasma vitamin B12 levels, Nat. Genet. 40 (2008) 1160-1162.

21. M. Takeuchi, N. Mizuki, A. Meguro, M.J. Ombrello, Y. Kirino, C. Satorius, J. Le, M. Blake, B. Erer, T. Kawagoe, D. Ustek, I. Tugal-Tutkun, E. Seyahi, Y. Ozyazgan, I. Sousa, F. Davatchi, V. Francisco, F. Shahram, B.S. Abdollahi, A. Nadji, N.M. Shafiee, F. Ghaderibarmi, S. Ohno, A. Ueda, Y. Ishigatsubo, M. Gadina, S.A. Oliveira, A. Gül, D.L. Kastner, E.F. Remmers, Dense genotyping of immune-related loci implicates host responses to microbial exposure in Behcet's disease susceptibility, Nat. Genet. 449 (2017) 438-443.

22. J. Chen, X. Zhang, J. Li, C. Song, Y. Jia, W. Xiong, Identification of a Novel ENUInduced Mutation in Mouse Tbx1 Linked to Human DiGeorge Syndrome, Neural Plast. (2016) 5836143. 
23. J.C. Fuchs, J.F. Linden, A. Baldini, A.S. Tucker AS, A defect in early myogenesis causes Otitis media in two mouse models of 22q11.2 Deletion Syndrome, Hum. Mol. Genet. 24 (2015) 1869-1882.

24. K. Bønnelykke, P. Sleiman, K. Nielsen, E. Kreiner-Møller, J.M. Mercader, D. Belgrave, H.T. den Dekker, A. Husby, A. Sevelsted, G. Faura-Tellez, L.J. Mortensen, L. Paternoster, R. Flaaten, A. Mølgaard, D.E. Smart, P.F. Thomsen, M.A. Rasmussen, S. Bonàs-Guarch, C. Holst, E.A. Nohr, R. Yadav, M.E. March, T. Blicher, P.M. Lackie, V.W. Jaddoe, A. Simpson, J.W. Holloway, L. Duijts, A. Custovic, D.E. Davies, D. Torrents, R. Gupta, M.V. Hollegaard, D.M. Hougaard, H. Hakonarson, H. Bisgaard, A genome-wide association study identifies CDHR3 as a susceptibility locus for early childhood asthma with severe exacerbations, Nat. Genet. 46 (2014) 51-55.

25. Y.A. Bochkov, K. Watters, S. Ashraf, T.F. Griggs, M.K. Devries, D.J. Jackson, A.C. Palmenberg, J.E. Gern, Cadherin-related family member 3, a childhood asthma susceptibility gene product, mediates rhinovirus $\mathrm{C}$ binding and replication, Proc. Natl. Acad. Sci. U S A 112 (2015) 5485-5490.

26. K. Bønnelykke, A.T. Coleman, M.D. Evans, J. Thorsen, J. Waage, N.H. Vissing, C.J. Carlsson, J. Stokholm, B.L. Chawes, L.E. Jessen, T.K. Fischer, Y.A. Bochkov, C. Ober, R.F. Lemanske Jr, D.J. Jackson, J.E. Gern, H. Bisgaard, CDHR3 Genetics and Rhinovirus C Respiratory Illnesses, Am. J. Respir. Crit. Care Med. 197 (2018) 589-594.

27. E.H. Mortensen, T. Lildholdt, N.P. Gammelgard, P.H. Christensen, Distribution of ABO blood groups in secretory otitis media and cholesteatoma, Clin. Otolaryngol. Allied Sci. 8 (1983) 263-265. 
1 28. K. Apostopoulos, E. Labropoulou, B. Konstantinos, S. Rhageed, E. Ferekidis, Blood group

2 in otitis media with effusion, ORL J. Otorhinolaryngol. Relat. Spec. 64 (2002) 433-435.

3 29. Q. Zhou, O. Soufan, J. Ewald, R.E.W. Hancock, N. Basu, J. Xia, NetworkAnalyst 3.0: a

4 visual analytics platform for comprehensive gene expression profiling and meta-analysis,

$5 \quad$ Nucleic Acids Res. 2019. doi:10.1093/nar/gkz240.

6 30. Aul, J.J., Anderson, K.W., Wadowsky, R., Doyle, W.J., Kingsley, L.A., Post, J.C., Ehrlich, G.D.^

7 Comparative evaluation of culture and PCR for the detection and determination of persistence of

8 bacterial strains and DNAs in the Chinchilla laniger model of otitis media. Annals of Otology,

$9 \quad$ Rhinology and Laryngology 107:508-513, 1998.

10 31. Buchinsky, F. J., Forbes, M., Hayes, J., Hu, F.Z., Greenberg, P., Post J.C., and Ehrlich, G.D.^

11 Phenotypic Plurality among Clinical Strains of nontypeable Haemophilus influenzae determined by

12 symptom severity in the Chinchilla model of Otitis Media. BMC Microbiology 14;7:56, 2007.

13 32. Shimoyama M, Hong W, Khampang P, Ehrlich GD, Bakaletz L, Kerschner, JE. The

14 Chinchilla Research Resource Database: resource for an otolaryngology disease model.

15 Database - The Journal of Biological Databases and Curation 2016 May 12 Epub pii:

$16 \quad$ baw073 doi:10.1093.

17 33. J.A. Bartlett, D.K. Meyerholz, C.L. Wohlford-Lenane, P.W. Naumann, N.H. Salzman, P.B.

18 McCray, Increased susceptibility to otitis media in a Splunc1-deficient mouse model, Dis.

$19 \quad$ Model Mech. 8 (2015) 501-508.

20 34. A. Kurabi, J. Lee, C. Wong, K. Pak, H. Hoffman, A.F. Ryan, S. Wasserman, The

21 inflammasome adaptor ASC contributes to multiple innate immune processes in the

22 resolution of otitis media, Innate Immun. 21 (2015) 203-214. 
1 35. D. Deniffel, B. Nuyen, K. Pak, K. Suzukawa, J. Hung, A. Kurabi, S.I. Wasserman, A.F.

2 Ryan, Otitis Media and Nasopharyngeal Colonization in ccl3(-/-) Mice, Infect Immun. 85

3 (2017). doi: 10.1128/IAI.00148-17.

4 36. H.W. Lim, K. Pak, A. Kurabi, A.F. Ryan, Lack of the hyaluronan receptor CD44 affects

5 the course of bacterial otitis media and reduces leukocyte recruitment to the middle ear,

$6 \quad$ BMC Immunol. 20 (2019) 20.

7 37. D. Punwani, B. Pelz, J. Yu, N.C. Arva, K. Schafernak, K. Kondratowicz, M. Makhija, J.M.

8 Puck, Coronin-1A: immune deficiency in humans and mice, J. Clin. Immunol. 35 (2015)

$9 \quad 100-107$.

10 38. A.S. Konduru, S. Matsuyama, B.C. Lee, K. Komatsu, J.D. Li, Curcumin Inhibits NTHi-

11 Induced MUC5AC Mucin Overproduction in Otitis Media via Upregulation of MAPK

12 Phosphatase MKP-1, Int. J. Inflam. 2017 (2017) 4525309.

13 39. C. Tian, B. Harris, K. Johnson, Ectopic mineralization and conductive hearing loss in

14 enpp1/asj mutant mice, a new model for otitis media and tympanosclerosis, PLoS One 11

$15 \quad$ (2016) e0168159.

16 40. J. Del-Pozo, N. MacIntyre, A. Azar, J. Glover, E. Milne, M. Cheeseman, Chronic otitis 17 media is initiated by a bulla cavitation defect in the FBXO11 mouse model, Dis. Model 18 Mech. 12 (2019). doi: 10.1242/dmm.037804.

19 41. M.R. Carpinelli, E.A. Kruse, B.D. Arhatari, M.A. Debrincat, J.M. Ogier, J.C. Bories, B.T. 20 Kile, R.A. Burt, Mice haploinsufficient for Ets1 and Fli1 display middle ear abnormalities 21 and model aspects of Jacobsen syndrome, Am. J. Pathol. 185 (2015) 1867-1876. 
42. Z. Wang, Q. He, X. Zhang, Y. Ma, F. Fan, Y. Dong, W. Xu, Y. Yin, Y. He, Innate antimicrobial and anti-chemotaxis properties of progranulin in an acute otitis media mouse model, Front. Immunol. 9 (2018) 2952.

43. K. Suzukawa, J. Tomlin, K. Pak, E. Chavez, A. Kurabi, A. Baird, S.I. Wasserman, A.F. Ryan, A mouse model of otitis media identifies HB-EGF as a mediator of inflammationinduced mucosal proliferation, PLoS One 9 (2014) e102739.

44. W. Yao, M. Frei, J. Pan, K. Pak, N. Webster, S.I. Wasserman, A.F. Ryan, C-Jun N-terminal Kinase (JNK) isoforms play differing roles in otitis media, BMC Immunol. 15 (2014) 46.

45. J. Zhang, M. Xu, Q. Zheng, Y. Zhang, W. Ma, Z. Zhang, Blocking macrophage migration inhibitory factor activity alleviates mouse acute otitis media in vivo, Immunol. Lett. 162 (2014) 101-108.

46. M. Crompton, T. Purnell, H.E. Tyrer, A. Parker, G. Ball, R.E. Hardisty-Hughes, R. Gale, D. Williams, C.H. Dean, M.M. Simon, A.M. Mallon, S. Wells, M.F. Bhutta, M.J. Burton, H. Tateossian, S.D.M. Brown, A mutation in Nischarin causes otitis media via LIMK1 and NF-кB pathways, PLoS Genet. 13 (2017) e1006969.

47. J.I. Woo, S. Oh, P. Webster, Y.J. Lee, D.J. Lim, S.K. Moon, NOD2/RICK-dependent $\beta$ defensin 2 regulation is protective for nontypeable Haemophilus influenzae-induced middle ear infection, PLoS One 9 (2014) e90933.

48. S.G. Shin, S.H. Koh, C.H. Woo, J.H. Lim, PAI-1 inhibits development of chronic otitis media and tympanosclerosis in a mouse model of otitis media, Acta Otolaryngol. 134 (2014) 1231-1238.

49. S. Maguire, J. Estabel, N. Ingham, S. Pearson, E. Ryder, D.M. Carragher, N. Walker, Sanger MGP Slc25a21 Project Team, J. Bussell, W.I. Chan, T.M. Keane, D.J. Adams, C.L. 
Scudamore, C.J. Lelliott, R. Ramírez-Solis, N.A. Karp, K.P. Steel, J.K. White, A.K.

Gerdin, Targeting of Slc25a21 is associated with orofacial defects and otitis media due to disrupted expression of a neighbouring gene, PLoS One 9 (2014) e91807.

4 50. X. Li, L. Xu, J. Li, B. Li, X. Bai, J.F. Strauss 3rd, Z. Zhang Z, H. Wang, Otitis media in

51. Y. Huang, Z. Wang, C. Jin, L. Wang, X. Zhang, W. Xu, Y. Xiang, W. Wang, X. He, Y.

Yin, Y. He, TLR2 promotes macrophage recruitment and Streptococcus pneumoniae clearance during mouse otitis media, Pediatr Res. 80 (2016) 886-893.

52. S.D. Brown, R.E. Hardisty-Hughes, P. Mburu P, Quiet as a mouse: dissecting the molecular and genetic basis of hearing, Nat. Rev. Genet. 9 (2008) 277-290.

53. A. Azar, C. Piccinelli, H. Brown, D. Headon, M. Cheeseman, Ectodysplasin signalling deficiency in mouse models of hypohidrotic ectodermal dysplasia leads to middle ear and nasal pathology, Hum. Mol. Genet. 25 (2016) 3564-3577.

54. A. Mulay, D.W. Hood, D. Williams, C. Russell, S.D.M. Brown, L. Bingle, M. Cheeseman, C.D. Bingle, Loss of the homeostatic protein BPIFA1, leads to exacerbation of otitis media severity in the Junbo mouse model, Sci Rep. 8 (2018) 3128.

55. J.P. Earl, N.D. Adappa, J. Krol, A.S. Bhat, S. Balashov, R.L. Ehrlich, J.N. Palmer, A.D. Workman, M. Blasetti, B. Sen, J. Hammond, N.A. Cohen, G.D. Ehrlich, J.C. Mell, Specieslevel bacterial community profiling of the healthy sinonasal microbiome using Pacific Biosciences sequencing of full-length 16A rRNA genes, Microbiome 23 (2018) 190.

56. K.L. Greathouse, J.R. White, A.J. Vargas, V.V. Bliskovsky, J.A. Beck, N. von Muhlinen, E.C. Polley, E.D. Bowman, M.A. Khan, A.I. Robles, T. Cooks, B.M. Ryan, N. Padgett, A.H. Dzutsev, G. Trinchieri, M.A. Pineda, S. Bilke, P.S. Meltzer, A.N. Hokenstad, T.M. 
Stickrod, M.R. Walther-Antonio, J.P. Earl, J.C. Mell, J.E. Krol, S.V. Balashov, A.S. Bhat, G.D. Ehrlich, A. Valm, C. Deming, S. Conlan, J. Oh, J.A. Segre, C.C. Harris, Interaction between the microbiome and TP53 in human lung cancer, Genome Biol. 19 (2018) 123.

57. J.T. Babauta, E. Atci, P.T. Ha, S.R. Lindemann, T. Ewing, D.R. Call, J.K. Frederickson, H. Beyenal, Localized electron transfer rates and microelectrode-based enrichment of microbial communities within a phototrophic microbial mat, Front. Microbiol. 5 (2014) 11.

58. R. D’Amore, U.Z. Ijaz, M. Schirmer, J.G. Kenny, R. Gregory, A.C. Darby, M. Shakya, M. Podar, C. Quince, N. Hall, A comprehensive benchmarking study of protocols and sequencing platforms for 16S rRNA community profiling, BMC Genomics 17 (2016) 55.

59. E.B. Fichot, R.S. Norman, Microbial phylogenetic profiling with the Pacific Biosciences sequencing platform, Microbiome 1 (2013) 10.

60. J.J. Mosher, E.L. Bernberg, O. Shevchenko, J. Kan, L.A. Kaplan, Efficacy of a $3^{\text {rd }}$ generation high-throughput sequencing platform for analyses of 16S rRNA genes from environmental samples, J. Microbiol. Methods 95 (2013) 175-181.

61. J.J. Mosher, B. Bowman, E.L. Bernberg, O. Shevchenko, J. Kan, J. Korlach, L.A. Kaplan, Improved performance of the PacBio SMRT technology for $16 \mathrm{~S}$ rDNA sequencing, J. Microbiol. Methods 104 (2014) 59-60.

62. P.D. Schloss, M.L. Jenior, C.C. Koumpouras, S.L. Westcott, S.K. Highlander, Sequencing 16S rRNA gene fragments using the PacBio SMRT DNA sequencing system, PeerJ 4 (2016) e1869.

63. E. Singer, B. Bushnell, D. Coleman-Derr, B. Bowman, R.M. Bowers, A. Levy, E.A. Gies, J.F. Cheng, A. Copeland, H.P. Klenk, S.J. Hallam, P. Hugenholtz, S.G. Tringe, T. Woyke, 
High-resolution phylogenetic microbial community profiling, ISME J. 10 (2016) 20202032.

3 64. J. Wagner, P. Coupland, H.P. Browne, T.D. Lawley, S.C. Francis, J. Parkhill, Evaluation of 4 PacBio sequencing for full-length bacterial 16S rRNA gene classification, BMC Microbiol. $5 \quad 16(2016) 274$.

6 65. V. Kunin, A. Engelbrektson, H. Ochman, P. Hugenholtz, Wrinkles in the rare biosphere: 7 pyrosequencing errors can lead to artificial inflation of diversity estimates, Environ.

$8 \quad$ Microbiol. $12(2010)$ 118-123.

9 66. C. Lee, C. Grasso, M.F. Sharlow, Multiple sequence alignment using partial order graphs, $10 \quad$ Bioinformatics 18 (2002) 452-464.

11 67. P.J. McMurdie, S. Holmes, Waste not, want not: why rarefying microbiome data is 12 inadmissible, PLoS Comput. Biol. 10 (2014) e1003531.

13 68. N.T. Ho, F. Li, S. Wang, L. Kuhn, metamicrobiomeR: an R package for analysis of microbiome relative abundance data using zero-inflated beta GAMLSS and meta-analysis

18 70. P.J. McMurdie, S. Holmes, Shiny-phyloseq: Web application for interactive microbiome analysis with provenance tracking, Bioinformatics 31 (2015) 282-283.

71. A.M. Eren, L. Maignien, W.J. Sul, L.G. Murphy, S.L. Grim, H.G. Morrison, M.L. Sogin, Oligotyping: Differentiating between closely related microbial taxa using 16S rRNA gene data, Methods Ecol. Evol. 4 (2013). 
72. B.J. Callahan, P.J. McMurdie, M.J. Rosen, A.W. Han, A.J. Johnson, S.P. Holmes, DADA2:

$2 \quad$ High-resolution sample inference from Illumina amplicon data, Nat. Methods 13 (2016)

$3 \quad 581-583$.

4 73. A.M. Eren, O.C. Esen, C. Quince, J.H. Vineis, H.G. Morrison, M.L. Sogin, T.O. Delmont,

5 Anvi'o: an advanced analysis and visualization platform for 'omics data, PeerJ 3 (2015)

$6 \quad \mathrm{e} 1319$.

7 74. N. Norskov-Lauritsen, M. Kilian, Reclassification of actinomycetemcomitans,

8 Haemophilus aphrophilus, Haemophilus paraphrophilus and Haemophilus segnis as

9 Aggregatibacter actinomycetemcomitans gen. nov., comb. nov., Aggregatibacter

10 aphrophilus comb. nov. and Aggregatibacter segnis comb. nov., and emended description

11 of Aggregatibacter aphrophilus to include V factor-dependent and V factor-independent

12 isolates, Int. J. Syst. Evol. Microbiol. 56 (2006) 2135-2146.

13 75. X. Didelot, R. Bowden, D.J. Wilson, T.E.A. Peto, D.W. Crook, Transforming clinical

14 microbiology with bacterial genome sequencing, Nat. Rev. Genet. 13 (2012) 601-612.

15 76. X. Didelot, A.S. Walker, T.E. Peto, D.W. Crook, D.J. Wilson, Within-host evolution of

16 bacterial pathogens, Nat. Rev. Microbiol. 14 (2016) 150-162.

17 77. E. Klemm, G. Dougan, Advances in Understanding Bacterial Pathogenesis Gained from

18 Whole-Genome Sequencing and Phylogenetics, Cell Host Microbe 19 (2016) 599-610.

19 78. S.K. Sheppard, D.S. Guttman, J.R. Fitzgerald, Population genomics of bacterial host

20 adaptation, Nat. Rev. Genet. 19 (2018) 549-565.

21 79. P.E. Chen, B.J. Shapiro, The advent of genome-wide association studies for bacteria, Curr. $22 \quad$ Opin. Microbiol. 25 (2015) 17-24. 
80. J.A. Lees, S.D. Bentley, Bacterial GWAS: not just gilding the lily, Nat. Rev. Microbiol. 14 (2016) 406.

81. R.A. Power, J. Parkhill, T. de Oliveira, Microbial genome-wide association studies: lessons from human GWAS, Nat. Rev. Genet. 18 (2017) 41.

82. E. Aun, A. Brauer, V. Kisand, T. Tenson, M. Remm, A k-mer-based method for the identification of phenotype-associated genomic biomarkers and predicting phenotypes of sequenced bacteria, PLoS Comput. Biol. 14 (2018) e1006434.

83. C. Collins, X. Didelot, A phylogenetic method to perform genome-wide association studies in microbes that accounts for population structure and recombination, PLoS Comput. Biol. 14 (2018) e1005958.

84. M. Jaillard, L. Lima, M. Tournoud, P. Mahé, A. Van Belkum, V. Lacroix, L. Jacob, A fast and agnostic method for bacterial genome-wide association studies: Bridging the gap between k-mers and genetic events, PLoS Genet. 14 (2018) e1007758.

85. J.D. Caballero, S.T. Clark, B. Coburn, Y. Zhang, P.W. Wang, S.L. Donaldson, D.E. Tullis, Y.C. Yau, V.J. Waters, D.M. Hwang, Selective sweeps and parallel pathoadaptation drive Pseudomonas aeruginosa evolution in the cystic fibrosis lung, MBio 6 (2015) e00981-15.

86. E.V. Sokurenko, D.L. Hasty, D.E. Dykhuizen, Pathoadaptive mutations: gene loss and variation in bacterial pathogens, Trends Microbiol 7 (1999) 191-195.

87. B.C. Young, C.H. Wu, N.C. Gordon, K. Cole, J.R. Price, E. Liu, A.E. Sheppard, S. Perera, J. Charlesworth, T. Golubchik, Severe infections emerge from commensal bacteria by adaptive evolution, eLife 6 (2017). doi: 10.7554/eLife.30637. 
88. K. Shen, P. Antalis, J. Gladitz, S. Sayeed, A. Ahmed, S. Yu, J. Hayes, S. Johnson, B. Dice, R. Dopico, Identification, distribution, and expression of novel genes in 10 clinical isolates of nontypeable Haemophilus influenzae, Infect. Immun. 73 (2005) 3479-3491.

89. J.S. Hogg, F.Z. Hu, B. Janto, R. Boissy, J. Hayes, R. Keefe, J.C. Post, G.D. Ehrlich,

Characterization and modeling of the Haemophilus influenzae core and supragenomes based on the complete genomic sequences of $\mathrm{Rd}$ and 12 clinical nontypeable strains, Genome Biol. 8 (2007) R103.

90. K. Shen, P. Antalis, J. Gladitz, B. Dice, B. Janto, R. Keefe, J. Hayes, A. Ahmed, R. Dopico, N. Ehrlich, J. Jocz, J. Kropp, S. Yu, L. Nistico, D.P. Greenberg, K. Barbadora, J.C. Post, G.D. Ehrlich, F.Z. Hu, Characterization, Distribution and Expression of Novel Genes Among Eight Clinical Isolates of Streptococcus pneumoniae, Infect. Immun. 74 (2006) 321-330.

91. N.L. Hiller, B. Janto, J.S. Hogg, R. Boissy, S. Yu, E. Powell, R. Keefe, N.E. Ehrlich, K. Shen, J. Hayes, K. Barbadora, W. Klimke, D. Dernovoy, T. Tatusova, J. Parkhill, S.D. Bentley, J.C. Post, G.D. Ehrlich, F.Z. Hu, Comparative Genomic Analyses of Seventeen Streptococcus pneumoniae Strains: Insights into the Pneumococcal Supragenome, J. Bacteriol. 189 (2007) 8186-8195.

92. C. Donati, N.L. Hiller, H. Tettelin, A. Muzzi, N.J. Croucher, S.V. Angiuoli, M. Oggioni, D. Riley, A. Covacci, S.D. Bentley, M. Kilian, G.D. Ehrlich, F.Z. Hu, R. Rappuoli, E.R. Moxon, V. Masignani, Structure and dynamics of the pan-genome of Streptococcus pneumoniae and closely related species, Genome Biol. 11 (2010) R107.

93. R. Boissy, A. Ahmed, B. Janto, J. Earl, B.J. Hall, J. Hogg, G.D. Pusch, N.L. Hiller, E. Powell, J. Hayes, S. Yu, S. Kathju, P. Stoodley, J.C. Post, G.D. Ehrlich, F.Z. Hu, Comparative Supragenomic Analyses among the Pathogens Staphylococcus aureus, 
Streptococcus pneumoniae, and Haemophilus influenzae Using a Modification of the Finite Supragenome Model, BMC Genomics 12 (2011) 187.

94. J.J. Davie, J. Earl, S.P.W. de Vries, A. Ahmed, F.Z. Hu, H.J. Bootsma, K. Stol, P.W.M. Hermans, R.M. Wadowsky, G.D. Ehrlich, J. Hays, A.A. Campagnari, Comparative Analysis and Supragenome Modeling of Twelve Moraxella catarrhalis Clinical Isolates, BMC Genomics 12 (2011) 70.

95. J.P. Earl, S.P.W. de Vries, A. Ahmed, E. Powell, M.P. Schultz, P.W.M. Hermans, D.J. Hill, C.I. Constantinidou, F.Z. Hu, H.J. Bootsma, G.D. Ehrlich, Comparative Genomic Analyses of the Moraxella Catarrhalis Serosensitive and Seroresistant Lineages Demonstrates Their Independent Evolution, Genome Biol. Evol. 8 (2016) 955-974.

96. R.H. Rau, R.L. Marvig, G.D. Ehrlich, S. Molin, L. Jelsbak, Deletion and acquisition of genomic content during early stage adaptation of Pseudomonas aeruginosa to a human host environment, Environ. Microbiol. 14 (2012) 2200-2211.

97. A.H.Y. Lee, S. Flibotte, S. Sinha, A. Paiero, R.L. Ehrlich, S. Balashov, G.D. Ehrlich, J.E.A. Zlosnik, J.C. Mell, C. Nislow, Phenotypic diversity and genotypic flexibility of Burkholderia cenocepacia during long-term infection of cystic fibrosis lungs, Genome Res. 27 (2017) 1-14.

98. R.D. Fleischmann, M.D. Adams, O. White, R.A. Clayton, E.F. Kirkness, A.R. Kerlavage, C.J. Bult, J.F. Tomb, B.A. Dougherty, J.M. Merrick, Whole-genome random sequencing and assembly of Haemophilus influenzae Rd, Science 269 (1995) 496-512.

99. A. Harrison, D.W. Dyer, A. Gillaspy, W.C. Ray, R. Mungur, M.B. Carson, H. Zhong, J. Gipson, M. Gipson, L.S. Johnson, Genomic sequence of an otitis media isolate of nontypeable Haemophilus influenzae: comparative study with H. influenzae serotype d, strain KW20, J. Bacteriol. 187 (2005) 4627-4636. 
100. M. De Chiara, D. Hood, A. Muzzi, D.J. Pickard, T. Perkins, M. Pizza, G. Dougan, R. Rappuoli, E.R. Moxon, M. Soriani, Genome sequencing of disease and carriage isolates of nontypeable Haemophilus influenzae identifies discrete population structure, Proc. Natl. Acad. Sci. U S A 111 (2014) 5439-5444.

101. R.A. Eutsey, N.L. Hiller, J.P. Earl, B.A. Janto, M.E. Dahlgren, A. Ahmed, E. Powell, M.P. Schultz, J.R. Gilsdorf, L. Zhang, Design and validation of a supragenome array for determination of the genomic content of Haemophilus influenzae isolates, BMC Genomics $14(2013) 484$.

102. J.M. Kress-Bennett, N.L. Hiller, R.A. Eutsey, E. Powell, M.J. Longwell, T. Hillman, T. Blackwell, B. Byers, J.C. Mell, J.C. Post, Identification and characterization of msf, a novel virulence factor in Haemophilus influenzae, PloS One 11 (2016) e0149891.

103. J. Moleres, A. Fernández-Calvet, R.L. Ehrlich, S. Martí, L. Pérez-Regidor, B. Euba, I. Rodríguez-Arce, S. Balashov, E. Cuevas, J. Liñares, Antagonistic Pleiotropy in the Bifunctional Surface Protein FadL (OmpP1) during Adaptation of Haemophilus influenzae to Chronic Lung Infection Associated with Chronic Obstructive Pulmonary Disease, mBio 9 (2018) e01176-01118.

104. M.M. Pettigrew, C.P. Ahearn, J.F. Gent, Y. Kong, M.C. Gallo, J.B. Munro, A. D’Mello, S. Sethi, H. Tettelin, T.F. Murphy, Haemophilus influenzae genome evolution during persistence in the human airways in chronic obstructive pulmonary disease, Proc. Natl. Acad. Sci. U S A 115 (2018) E3256-E3265.

105. A. Aziz, D.S. Sarovich, E. Nosworthy, J. Beissbarth, A.B. Chang, H. Smith-Vaughan, E.P. Price, T.M. Harris, Molecular signatures of non-typeable Haemophilus influenzae lung 
adaptation in paediatric chronic lung disease, bioRxiv (2019) 614214. https://doi.org/10.1101/614214.

106. N. Topaz, D. Boxrud, A.C. Retchless, M. Nichols, H.Y. Chang, F. Hu, X. Wang, BMScan:

4 using whole genome similarity to rapidly and accurately identify bacterial meningitis causing species, BMC Infect. Dis. 18 (2018) 405.

107. M. Pinto, A. González-Díaz, M. Machado, S. Duarte, L. Vieira, J. Carriço, S. Marti, M. Bajanca-Lavado, J. Gomes, Insights into the population structure and pan-genome of Haemophilus influenzae, Infect. Genet. Evol. 67 (2019) 126-135.

108. D. Cleary, V. Devine, D. Morris, K. Osman, R. Gladstone, S. Bentley, S. Faust, S. Clarke, Pneumococcal vaccine impacts on the population genomics of non-typeable Haemophilus influenzae, Microb. Genom. 4 (2018). doi: 10.1099/mgen.0.000209.

109. R.D. Stewart, M.D. Auffret, A. Warr, A.H. Wiser, M.O. Press, K.W. Langford, I. Liachko, T.J. Snelling, R.J. Dewhurst, A.W. Walker, R. Roehe, M. Watson, Assembly of 913 microbial genomes from metagenomic sequencing of the cow rumen, Nat. Commun. 9 (2018) 870 .

110. D.M. Bickhart, M. Watson, S. Koren, K. Panke-Buisse, L.M. Cersosimo, M.O. Press, C.P. Van Tassell, J.A.S. Van Kessel, B.J. Haley, S.W. Kim, C. Heiner, G. Suen, K. Bakshee, I. Liachko, S.T. Sullivan, P.R. Myer, J. Ghurye. M. Pop, P.J. Weimer, A.M. Phillippy, T.P.L. Smith, Assignment of virus and antimicrobial resistance genes to microbial hosts in a complex microbial community by combined long-read assembly and proximity ligation, Genome Biol. 153 (2019). doi: https://doi.org/10.1101/491175. 
111. A.E.K. Dichosa, A.R. Daughton, K.G. Reitenga, M.S. Fitzsimons, C.S. Han, Capturing and cultivating single bacterial cells in gel microdroplets to obtain near-complete genomes, Nat. Protoc. 9 (2014) 610.

4 112. A.E.K. Dichosa, D.W. Davenport, P.E. Li, S.A. Ahmed, H. Daligault, C.D. Gleasner, Y.

Kunde, K. McMurry, C.C. Lo, K.G. Reitenga, A.R. Daughton, C. Shen, S. Frietze, D. Wang, S.L. Johnson, D.I. Drautz-Moses, S. Schuster, P.S. Chain, C. Han, Draft Genome Sequence of Thauera sp. Strain SWB20, Isolated from a Singapore Wastewater Treatment Facility Using Gel Microdroplets, Genome Announc, 3 (2015) e00132-15.

113. R. Moxon, C. Bayliss, D. Hood, Bacterial contingency loci: the role of simple sequence DNA repeats in bacterial adaptation, Annu. Rev. Genet. 40 (2006) 307-333.

114. P.M. Power, W.A. Sweetman, N.J. Gallacher, M.R. Woodhall, G.A. Kumar, E.R. Moxon, D.W. Hood, Simple sequence repeats in Haemophilus influenzae, Infect. Genet. Evol. 9 (2009) 216-28.

115. L.V. Blakeway, A. Tan, I.R.A. Peak, K.L. Seib, Virulence determinants of Moraxella catarrhalis: distribution and considerations for vaccine development, Microbiology 163 (2017) 1371-1384.

116. Y.N. Srikhanta, T.L. Maguire, K.J. Stacey, S.M. Grimmond, M.P. Jennings, The phasevarion: a genetic system controlling coordinated, random switching of expression of multiple genes, Proc. Natl. Acad. Sci. U S A 102 (2005) 5547-5551.

117. Y.N. Srikhanta, K.L. Fox, M.P. Jennings, The phasevarion: phase variation of type III DNA methyltransferases controls coordinated switching in multiple genes, Nat. Rev. Microbiol. 8 (2010) 196-206. 
118. J.M. Atack, Y.N. Srikhanta, K.L. Fox, J.A. Jurcisek, K.L. Brockman, T.A. Clark, M. Boitano, P.M. Power, F.E. Jen, A.G. McEwan, S.M. Grimmond, A.L. Smith, S.J. Barenkamp, J. Korlach, L.O. Bakaletz, M.P. Jennings, A biphasic epigenetic switch controls immunoevasion, virulence and niche adaptation in non-typeable Haemophilus influenzae, Nat. Commun. 6 (2015) 7828.

119. L.V. Blakeway, P.M. Power, F.E. Jen, S.R. Worboys, M. Boitano, T.A. Clark, J. Korlach, L.O. Bakaletz, M.P. Jennings, I.R. Peak, K.L. Seib, ModM DNA methyltransferase methylome analysis reveals a potential role for Moraxella catarrhalis phasevarions in otitis media, FASEB J. 28 (2014) 5197-5207.

120. A.S. Manso, M.H. Chai, J.M. Atack, L. Furi, M. De Ste Croix, R. Haigh, C. Trappetti, A.D. Ogunniyi, L.K. Shewell, M. Boitano, T.A. Clark, J. Korlach, M. Blades, E. Mirkes, A.N. Gorban, J.C. Paton, M.P. Jennings, M.R. Oggioni, A random six-phase switch regulates pneumococcal virulence via global epigenetic changes, Nat. Commun. 5 (2014) 5055.

121. Capecchi B, Serruto D, Adu-Bobie J, Rappuoli R, Pizza M, The genome revolution in vaccine research, Curr. Issues Mol. Biol. 6 (2004) 17-27.

122. F.V. Filipp, Precision medicine driven by cancer systems biology, Cancer Metastasis Rev. 36 (2017) 91-108.

123. G. Rossi, M. Ignatiadis, Promises and pitfalls of using liquid biopsy for precision medicine, Cancer Res. 79 (2019) 2798-2804.

124. S. Morganti, P. Tarantino, E. Ferraro, P. D’Amico, G. Viale, D. Trapani, B.A. Duso, G. Curigliano, Complexity of genome sequencing and reporting: Next generation sequencing (NGS) technologies and implementation of precision medicine in real life, Crit. Rev. Oncol. Hematol. 133 (2019) 171-182. 
125. J.W. Leiding, M. Ballow, Precision medicine in the treatment of primary immunodeficiency diseases, Curr. Opin. Allergy Clin. Immunol. 18 (2018) 159-166.

126. M. Skov, C.R. Hansen, T. Pressler, Cystic fibrosis - an example of personalized and precision medicine, APMIS 127 (2019) 352-360.

127. M.W. Pletz, M. Bauer, A.A. Brakhage, One step closer to precision medicine for infectious diseases, Lancet Infect. Dis. 19 (2019) 564-565.

128. C.N. Spaulding, R.D. Klein, H.L. Schreiber 4th, J.W. Janetka, S.J. Hultgren, Precision antimicrobial therapeutics: The path of least resistance? NPJ Biofilms Microbiomes 4 (2018) 4 .

129. M.R. Atreya, H.R. Wong, Precision medicine in pediatric sepsis, Curr. Opin. Pediatr. 31 (2019) 322-327.

130. S. Mahomed, N. Padayatchi, J. Singh, K. Naidoo, Precision medicine in resistant tuberculosis: Treat the correct patient, at the correct time, with the correct drug, J. Infect. 78 (2019) 261-268.

131. Samuels TL, Yan JC, Khampang P, Dettmar PW, MacKinnon A, Hong W, Johnston N, Papsin BC, Chun RH, McCormick ME, Kerschner JE. Association of gel-forming mucins and aquaporin gene expression with hearing loss, effusion viscosity and inflammation in otitis media with effusion. JAMA Otolaryngology-Head \& Neck Surgery 2017;143(8):810-

\section{7}

132. Val S, Jeong S, Poley M, Krueger A, Nino G, Brown K, Preciado D. Purification and characterization of microRNAs within middle ear fluid exosomes: implication in otitis media pathophysiology. Pediatric Research 2017;81(6):911-918. 
1 133. Samuels TL, Yan J, Khampang P, MacKinnon A, Hong W, Johnston N, Kerschner JE.

2 Association of microRNA 146 with middle ear hyperplasia in pediatric otitis media.

$3 \quad$ International Journal of Pediatric Otorhinolaryngology 2016;88(9);104-108.

4 134. C.G. Park, S. Kim, E.J. Lee, H.S. Jeon, S. Han, Clinical relevance of point mutations in the $523 \mathrm{~S}$ rRNA gene in helicobacter pylori eradication: A prospective, observational study, $6 \quad$ Medicine (Baltimore) 97 (2018) e11835.

7 135. C. de la Fuente-Nunez, M.D. Torres, F.J. Mojica, T.K. Lu, Next-generation precision 8 antimicrobials: Towards personalized treatment of infectious diseases, Curr. Opin. $9 \quad$ Microbiol. 37 (2017) 95-102.

10 136. R.P. Venekamp, S.L. Sanders, P.P. Glasziou PP, C.C. Del Mar, M.M. Rovers, Antibiotics 11 for acute otitis media in children, Cochrane Database Syst. Rev. 6 (2015) CD000219.

12 137. A. Wafi, R. Mirnezami, Translational -omics: Future potential and current challenges in 13 precision medicine, Methods 151 (2018) 3-11.

14 138. N.A. Francis, C.A. Waldron, R. Cannings-John, E. Thomas-Jones, T. Winfield, V. Shepherd, D. Harris, K. Hood, D. Fitzsimmons, A. Roberts, C.V. Powell, M. Gal, S. Jones, C.C. Butler, Oral steroids for hearing loss associated with otitis media with effusion in children aged 2-8 years: the OSTRICH RCT, Health Technol. Assess. 22 (2018) 1-114.

139. R.W. Ranakusuma, Y. Pitoyo, E.D. Safitri, S. Thorning, E.M. Beller, S. Sastroasmoro, C.B. Del Mar, Systemic corticosteroids for acute otitis media in children, Cochrane

140. J.A. Lewnard, P.A. Tähtinen, M.K. Laine, L. Lindholm, J. Jalava, P. Huovinen, M. Lipsitch, A. Ruohola, Impact of Antimicrobial Treatment for Acute Otitis Media on 
Carriage Dynamics of Penicillin-Susceptible and Penicillin-Nonsusceptible Streptococcus pneumoniae, J. Infect. Dis. 218 (2018) 1356-1366.

141. A. Ruohola, M.K. Laine, P.A. Tähtinen, Effect of Antimicrobial Treatment on the Resolution of Middle-Ear Effusion After Acute Otitis Media, J. Pediatric Infect. Dis. Soc. 7 (2018) 64-70.

142. A. Hoberman, J.L. Paradise, H.E. Rockette, D.H. Kearney, S. Bhatnagar, T.R. Shope, J.M. Martin, M. Kurs-Lasky, S.J. Copelli, D.K. Colborn, S.L. Block, J.J. Labella, T.G. Lynch, N.L. Cohen, M. Haralam, M.A. Pope, J.P. Nagg, M.D. Green, N. Shaikh, Shortened Antimicrobial Treatment for Acute Otitis Media in Young Children, N. Engl. J. Med. 375 (2016) 2446-2456.

143. M. Te Molder, M.L. de Hoog, C.S. Uiterwaal, C.K. van der Ent, H.A. Smit, A.G. Schilder, R.A. Damoiseaux, R.P. Venekamp, Antibiotic Treatment for First Episode of Acute Otitis Media Is Not Associated with Future Recurrences, PLoS One 11 (2016) e0160560.

144. N. Shaikh, E.E. Dando, M.L. Dunleavy, D.L. Curran, J.M. Martin, A. Hoberman, K.J. Smith, A Cost-Utility Analysis of 5 Strategies for the Management of Acute Otitis Media in Children, J. Pediatr. 189 (2017) 54-60.e3.

145. G.K. Spurling, C.B. Del Mar, L. Dooley, R. Foxlee, R. Farley, Delayed antibiotic prescriptions for respiratory infections, Cochrane Database Syst. Rev. 9 (2017) CD004417.

146. R. Yang, V. Sabharwal, O.S. Okonkwo, N. Shlykova, R. Tong, L.Y. Lin, W. Wang, S. Guo, J.J. Rosowski, S.I. Pelton, D.S. Kohane, Treatment of otitis media by transtympanic delivery of antibiotics, Sci. Transl. Med. 8 (2016) 356ra120. 
147. A. Kurabi, K.A. Beasley, L. Chang, J. McCann, K. Pak, A.F. Ryan, Peptides actively transported across the tympanic membrane: Functional and structural properties, PLoS One 12 (2017) e0172158.

148. A. Kurabi, D. Schaerer, L. Chang, K. Pak, A.F. Ryan, Optimisation of peptides that actively cross the tympanic membrane by random amino acid extension: a phage display study, J. Drug Target 26 (2018) 127-134.

149. A. Kurabi, D. Schaerer, V. Noack, M. Bernhardt, K. Pak, T. Alexander, J. Husseman, Q. Nguyen, J.P. Harris, A.F. Ryan, Active Transport of Peptides Across the Intact Human Tympanic Membrane, Sci. Rep. 8 (2018) 11815.

150. Xu Q, Gill S, Xu L, Gonzalez E, Pichichero ME. Comparative Analysis of Microbiome in Nasopharynx and Middle Ear in Young Children With Acute otitis Media. Front Genet. 2019 Nov 19;10:1176.

151. T. Mrkvan, S.I. Pelton, J. Ruiz-Guinazu, A.A. Palmu, D. Borys, Effectiveness and impact of the 10-valent pneumococcal conjugate vaccine, PHiD-CV: review of clinical trials and post-marketing experience, Expert Rev. Vaccines 17 (2018) 797-818.

152. X. Zhou, C. de Luise, M. Gaffney, C.W. Burt, D.A. Scott, N. Gatto, K.J. Center, National impact of 13-valent pneumococcal conjugate vaccine on ambulatory care visits for otitis media in children under 5 years in the United States, Int. J. Pediatr. Otorhinolaryngol. 119 (2019) 96-102.

153. A.C. Fortanier, R.P. Venekamp, C.W. Boonacker, E. hak, A.G. Schilder, E.A. Sanders, R.A. Damoiseaux, Pneumococcal conjugate vaccines for preventing acute otitis media in children, Cochrane Database Syst. Rev. 5 (2019) CD001480. 
154. M. Pichichero, R. Kaur, D.A. Scott, W.C. Gruber, J. Trammel, A. Almudevar, K.J. Center, Effectiveness of 13-valent pneumococcal conjugate vaccination for protection against acute otitis media caused by Streptococcus pneumoniae in healthy young children: a prospective observational study, Lancet Child Adolesc. Health 2 (2018) 561-568.

155. R. Dagan, S. Pelton, L. Bakaletz, R. Cohen, Prevention of early episodes of otitis media by pneumococcal vaccines might reduce progression to complex disease, Lancet Infect. Dis. 16 (2016) 480-492.

156. R. Dagan, S. Pelton, L. Bakaletz, R. Cohen, First Otitis Media and Pneumococcal Conjugate Vaccine Serotypes in Infants, Pediatr. Infect. Dis. J. 37 (2018) e351-e352.

157. R. Kaur, J.R. Casey, M.E. Pichichero, Emerging Streptococcus pneumoniae Strains Colonizing the Nasopharynx in Children After 13-valent Pneumococcal Conjugate Vaccination in Comparison to the 7-valent Era, 2006-2015, Pediatr. Infect. Dis. J. 35 (2016) 901-906.

158. D. Greenberg, P.A. Hoover, T. Vesikari, C. Peltier, D.C. Hurley, R.D. McFetridge, M. Dallas, J. Hartzel, R.D. Marchese, B.G. Coller, J.E. Stek, C. Abeygunawardana, M.A. Winters, J.E. MacNair, N.S. Pujar, L. Musey, Safety and immunogenicity of 15-valent pneumococcal conjugate vaccine (PCV15) in healthy infants, Vaccine 36 (2018) 68836891.

159. H.L. Stacey, J. Rosen, J.T. Peterson, A. Williams-Diaz, V. Gakhar, T.M. Sterling, C.J. Acosta, K.M. Nolan, J. Li, A. Pedley, P. Benner, C. Abeygunawardana, M. Kosinski, W.J. Smith, H. Pujar, L.K. Musey, Safety and immunogenicity of 15-valent pneumococcal conjugate vaccine (PCV-15) compared to PCV-13 in healthy older adults. Hum. Vaccin. Immunother. 15 (2019) 530-539. 
160. J.T. Peterson, H.L. Stacey, J.E. MacNair, J. Li, J.S. Hartzel, T.M. Sterling, P. Benner, G.M. Tamms, L.K. Musey, Safety and immunogenicity of 15-valent pneumococcal conjugate vaccine compared to 13 -valent pneumococcal conjugate vaccine in adults $\geq 65$ years of age previously vaccinated with 23 -valent pneumococcal polysaccharide vaccine, Hum. Vaccin. Immunother. 15 (2019) 540-548.

161. M.E. Pichichero, Pneumococcal whole-cell and protein-based vaccines: changing the paradigm, Expert Rev. Vaccines 16 (2017) 1181-1190.

162. M.R. Alderson, Status of research and development of pediatric vaccines for Streptococcus pneumoniae, Vaccine 34 (2016) 2959-2961.

163. G. Gabutti, C. Azzari, P. Bonanni, R. Prato, A.E. Tozzi, A. Zanetti, G. Zuccotti, Pertussis. Hum. Vaccin. Immunother. 11 (2015) 108-117.

164. E. Hoe, L.K. Boelsen, Z.Q. Toh, G.W. Sun, G.C. Koo, A. Balloch, R. Marimla, E.M. Dunne, L. Tikoduadua, F.M. Russell, C. Satzke, E.K. Mulholland, P.V. Licciardi, Reduced IL-17A Secretion Is Associated with High Levels of Pneumococcal Nasopharyngeal Carriage in Fijian Children, PLoS One 10 (2015) e0129199.

165. J.J. Campo, T.Q. Le, J.V. Pablo, C. Hung, A.A. Teng, H. Tettelin, A. Tate, W.P. Hanage, M.R. Alderson, X. Liang, R. Malley, M. Lipsitch, N.J. Croucher, Panproteome-wide analysis of antibody responses to whole cell pneumococcal vaccination, Elife (2018) 7. doi: 10.7554/eLife.37015.

166. K.L. Moffitt, P. Yadav, D.M. Weinberger, P.W. Anderson, R. Malley, Broad antibody and T cell reactivity induced by a pneumococcal whole-cell vaccine, Vaccine 30 (2012) 43164322. 
167. S.C. David, Z. Laan, V. Minhas, A.Y. Chen, J. Davies, T.R. Hirst, S.R. McColl, M. Alsharifi, J.C. Paton, Enhanced safety and immunogenicity of a pneumococcal surface antigen A mutant whole-cell inactivated pneumococcal vaccine, Immunol. Cell Biol. (2019). doi: 10.1111/imcb.12257.

168. M. Giufre, M. Fabiani, R. Cardines, F. Riccardo, M.G. Caporali, F. D’Ancona, P. Pezzotti, M. Cerquetti, Increasing trend in invasive non-typeable Haemophilus influenzae disease and molecular characterization of the isolates, Italy, 2012-2016, Vaccine 36 (2018) 66156622.

169. S. Naito, N. Takeuchi, M. Ohkusu, A. Takahashi-Nakaguchi, H. Takahashi, N. Imuta, J. Nishi, K. Shibayama, M. Matsuoka, Y. Sasaki, N. Ishiwada, Clinical and Bacteriologic Analysis of Nontypeable Haemophilus influenzae Strains Isolated from Children with Invasive Diseases in Japan from 2008 to 2015, J. Clin. Microbiol. 56 (2018). doi: 10.1128/JCM.00141-18.

170. M.M. Pettigrew, C.P. Ahearn, J.F. Gent, Y. Kong, M.C. Gallo, J.B. Munro, A. D’Mello, S. Sethi, H. Tettelin, T.F. Murphy, Haemophilus influenzae genome evolution during persistence in the human airways in chronic obstructive pulmonary disease, Proc. Natl. Acad. Sci. U S A 115 (2018) E3256-E3265.

171. R. Prymula, P. Peeters, V. Chrobok, P. Kriz, E. Novakova, E. Kaliskova, I. Kohl, P. Lommel, J. Poolman, J.P. Prieels, L. Schuerman, Pneumococcal capsular polysaccharides conjugated to protein D for prevention of acute otitis media caused by both Streptococcus pneumoniae and non-typable Haemophilus influenzae: a randomised double-blind efficacy study, Lancet 367 (2006) 740-748. 
172. C. Clarke, L.O. Bakaletz, J. Ruiz-Guinazu, D. Borys, T. Mrkvan, Impact of protein D-

2 containing pneumococcal conjugate vaccines on non-typeable Haemophilus influenzae

3 acute otitis media and carriage, Expert Rev. Vaccines 16 (2017) 1-14.

4 173. M.R. van den Bergh, J. Spijkerman, K.M. Swinnen, N.A. Francois, T.G. Pascal, D. Borys,

5 L. Schuerman, E.P. Ijzerman, J.P. Bruin, A. van der Ende, R.H. Veenhoven, E.A. Sanders,

6 Effects of the 10-valent pneumococcal nontypeable Haemophilus influenzae protein D-

7 conjugate vaccine on nasopharyngeal bacterial colonization in young children: a

8 randomized controlled trial, Clin. Infect. Dis. 56 (2013) e30-39.

9 174. F. Jalalvand, K. Riesbeck, Update on non-typeable Haemophilus influenzae-mediated

10 disease and vaccine development, Expert Rev. Vaccines 17 (2018) 503-512.

11 175. L.A. Novotny, K.L. Brockman, E.M. Mokrzan, J.A. Jurcisek, L.O. Bakaletz, Biofilm

12 biology and vaccine strategies for otitis media due to nontypeable Haemophilus influenzae,

13 J. Pediatr. Infect. Dis. 14 (2019) 69-77.

14 176. M.N. Khan, D. Ren, R. Kaur, S. Basha, R. Zagursky, M.E. Pichichero, Developing a 15 vaccine to prevent otitis media caused by nontypeable Haemophilus influenzae, Expert $16 \quad$ Rev. Vaccines 15 (2016) 863-878.

17 177. G. Leroux-Roels, P. Van Damme, W. Haazen, S. Shakib, M. Caubet, E. Aris, J.M.

18 Devaster, M. Peeters, Phase I, randomized, observer-blind, placebo-controlled studies to 19 evaluate the safety, reactogenicity and immunogenicity of an investigational non-typeable 20 Haemophilus influenzae (NTHi) protein vaccine in adults, Vaccine 34 (2016) 3156-3163.

21 178. J. Berglund, P. Vink, F. Tavares Da Silva, P. Lestrate, D. Boutriau, Safety, 22 immunogenicity, and antibody persistence following an investigational Streptococcus 
pneumoniae and Haemophilus influenzae triple-protein vaccine in a phase 1 randomized controlled study in healthy adults, Clin. Vaccine Immunol. 21 (2014) 56-65.

179. P. Van Damme, G. Leroux-Roels, C. Vandermeulen, I. De Ryck, A. Tasciotti, M. Dozot, L. Moraschini, M. Testa, A.K. Arora, Safety and immunogenicity of non-typeable Haemophilus influenzae-Moraxella catarrhalis vaccine, Vaccine 37 (2019) 3113-3122.

180. M.K. Tandon, M. Phillips, G. Waterer, M. Dunkley, P. Comans, R. Clancy, Oral immunotherapy with inactivated nontypeable Haemophilus influenzae reduces severity of acute exacerbations in severe COPD, Chest 137 (2010) 805-811.

181. R.L. Clancy, M.L. Dunkley, J. Sockler, C.F. McDonald, Multi-site placebo-controlled randomised clinical trial to assess protection following oral immunisation with inactivated non-typeable Haemophilus influenzae in chronic obstructive pulmonary disease, Intern. Med. J. 46 (2016) 684-693.

182. E. Teo, K. Lockhart, S.N. Purchuri, J. Pushparajah, A.W. Cripps, M.L. van Driel, Haemophilus influenzae oral vaccination for preventing acute exacerbations of chronic bronchitis and chronic obstructive pulmonary disease, Cochrane Database Syst. Rev. 6 (2017) CD010010.

183. L.A. Novotny, J.D. Clements, S.D. Goodman, L.O. Bakaletz, Transcutaneous Immunization with a Band-Aid Prevents Experimental Otitis Media in a Polymicrobial Model, Clin. Vaccine Immunol. 24 (2017) e00563.

184. L.V. Michel, R. Kaur, M. Zavorin, K. Pryharski, M.N. Khan, C. LaClair, M. O’Neil, Q. Xu, M.E. Pichichero, Intranasal coinfection model allows for assessment of protein vaccines against nontypeable Haemophilus influenzae in mice, J. Med. Microbiol. 67 (2018) 1527-1532. 
1 185. L.E. Winter, S.J. Barenkamp, Immunogenicity of Nontypeable Haemophilus influenzae

2 Outer Membrane Vesicles and Protective Ability in the Chinchilla Model of Otitis Media,

3 Clin. Vaccine Immunol. 24 (2017).

4 186. A.C. Perez, T.F. Murphy, A Moraxella catarrhalis vaccine to protect against otitis media 5 and exacerbations of COPD: An update on current progress and challenges, Hum. Vaccin.

$6 \quad$ Immunother. 13 (2017) 2322-2331.

7 187. D. Ren, M.E. Pichichero, Vaccine targets against Moraxella catarrhalis, Expert Opin. Ther. 8 Targets $20(2016)$ 19-33.

9 188. M.E. Pichichero, J.R. Casey, A. Almudevar, Nonprotective responses to pediatric vaccines 10 occur in children who are otitis prone, Pediatr. Infect. Dis. J. 32 (2013) 1163-1168.

11 189. M.E. Pichichero, Ten-Year Study of the Stringently Defined Otitis-prone Child in 12 Rochester, NY, Pediatr. Infect. Dis. J. 35 (2016) 1033-1039.

13 190. S. Basha, M.E. Pichichero, Poor memory B cell generation contributes to non-protective 14 responses to DTaP vaccine antigens in otitis-prone children, Clin. Exp. Immunol. 182 $15 \quad$ (2015) 314-322.

16 191. S.K. Sharma, J.R. Casey, M.E. Pichichero, Reduced memory CD4+ T-cell generation in 17 the circulation of young children may contribute to the otitis-prone condition, J. Infect. Dis. $18204(2011) 645-653$.

19 192. S.K. Sharma, J.R. Casey, M.E. Pichichero, Reduced serum IgG responses to pneumococcal 20 antigens in otitis-prone children may be due to poor memory B-cell generation, J. Infect.

21 Dis. 205 (2012) 1225-1229. 
193. S. Basha, R. Kaur, T.R. Mosmann, M.E. Pichichero, Reduced T-Helper 17 Responses to

Streptococcus pneumoniae in Infection-Prone Children Can Be Rescued by Addition of Innate Cytokines, J. Infect. Dis. 215 (2017) 1321-1330.

194. S. Basha, M.E. Pichichero, Decreased TNF family receptor expression on B-cells is associated with reduced humoral responses to Streptococcus pneumoniae infections in young children, Cell Immunol. 320 (2017) 11-19.

195. R. Kaur, J.R. Casey, M.E. Pichichero, Serum antibody response to five Streptococcus pneumoniae proteins during acute otitis media in otitis-prone and non-otitis-prone children, Pediatr. Infect. Dis. J. 30 (2011) 645-650.

196. Q. Xu, J.R. Casey, E. Newman, M.E. Pichichero, Otitis-Prone Children Have Immunologic Deficiencies in Naturally Acquired Nasopharyngeal Mucosal Antibody Response after Streptococcus pneumoniae Colonization, Pediatr. Infect. Dis. J. 35 (2016) 54-60.

197. D. Ren, T.F. Murphy, E.R. Lafontaine, M.E. Pichichero, Stringently Defined Otitis Prone Children Demonstrate Deficient Naturally Induced Mucosal Antibody Response to Moraxella catarrhalis Proteins, Front. Immunol. 8 (2017) 953.

198. D. Ren, A.L. Almudevar, T.F. Murphy, E.R. Lafontaine, A.A. Campagnari, N. LukeMarshall, M.E. Pichichero, Serum antibody response to Moraxella catarrhalis proteins in stringently defined otitis prone children, Vaccine 37 (2017) 4637-4645.

199. A. Harrison, L.G. Dubois, L.S. John-Williams, M.A. Moseley, R.L. Hardison, D.R. Heimlich, A. Stoddard, J.E. Kerschner, S.S. Justice, J.W. Thompson, Comprehensive proteomic and metabolomic signatures of nontypeable Haemophilus influenzae-induced acute otitis media reveal bacterial aerobic respiration in an immunosuppressed environment, Mol. Cell. Proteomics, 15 (2016) 1117-1138. 
1 200. B. Baddal, A. Muzzi, S. Censini, R.A. Calogero, G. Torricelli, S. Guidotti, A.R. Taddei, A.

2 Covacci, M. Pizza, R. Rappuoli, Dual RNA-seq of nontypeable Haemophilus influenzae

3 and host cell transcriptomes reveals novel insights into host-pathogen cross talk, MBio 6

$4 \quad$ (2015) e01765-15. 


\section{Legend to Figures}

2

3 Fig. 1. Analysis of the Critical Assessment of Metagenome Interpretation community (>250

4 species) demonstrated the ability of MDx to identify and determine abundances of hundreds of

5 species over $>3$ logs of variance. Reproduced from reference 52 which is an author owned paper

6

7 Fig. 2. Twenty bilateral microbiomes for chronic otitis media with effusion. The top 18 most

8 prevalent species are shown as colored bars. Reproduced from reference 52 which is an author

9 owned paper

10 
Table 1. Genome-wide significant ${ }^{\mathrm{a}}$ loci from genome-wide association studies on otitis media

\begin{tabular}{|c|c|c|c|c|c|c|c|}
\hline Ref & $d b S N P I D$ & Gene & Variant $^{b}$ & $\begin{array}{c}\text { All } \\
\text { MAF }\end{array}$ & $\begin{array}{l}\text { NFE } \\
\text { MAF }\end{array}$ & $\begin{array}{c}\text { Lat } \\
\text { MAF }\end{array}$ & $\begin{array}{c}\text { Afr } \\
\text { MAF }\end{array}$ \\
\hline 11 & rs2406176 & TMPRSS15 & c. $1172-3049 \mathrm{~A}>\mathrm{C}$ & 0.72 & 0.75 & 0.80 & 0.61 \\
\hline 12,13 & rs681343 & $F U T 2^{\mathrm{c}}$ & c. $249 \mathrm{C}>\mathrm{T}(\mathrm{p} . \mathrm{Tyr} 83=)$ & 0.39 & 0.47 & 0.27 & 0.50 \\
\hline 11 & rs4825724 & ClGALTICl-[1-CT47B1 & Intergenic & 0.47 & 0.40 & 0.45 & 0.63 \\
\hline 12,13 & $\operatorname{rs} 1978060^{c}$ & $T B X 1$ & c. $410+722 A>G$ & 0.64 & 0.61 & 0.46 & 0.75 \\
\hline 12,13 & rs2808290 & $R A B 18--[]-M K X$ & Intergenic & 0.38 & 0.49 & 0.40 & 0.18 \\
\hline 12 & rs7174062 & SPATA8--[]-ARRDC4 & Intergenic & 0.78 & 0.72 & 0.81 & 0.89 \\
\hline 12,13 & $\operatorname{rs} 4329147^{\mathrm{d}}$ & HLA-DRB5--[]--HLA-DQA1 & Intergenic & 0.84 & 0.85 & 0.88 & 0.83 \\
\hline 12,13 & rs8176643 & $A B O^{\mathrm{c}}$ & c. $28+869 \mathrm{delG}$ & 0.14 & 0.20 & 0.13 & 0.04 \\
\hline 12,13 & rs1802575 & EFEMP1 & c. $* 1004 \mathrm{C}>\mathrm{G}$ & 0.07 & 0.11 & 0.05 & 0.03 \\
\hline 12,13 & rs5829676 & NT5CIB-RDH14--[]--OSRI & Intergenic & 0.31 & 0.40 & 0.39 & 0.19 \\
\hline 11 & rs885932 & $H L A-G-[]-H L A-H$ & Intergenic & 0.11 & 0.15 & 0.08 & 0.05 \\
\hline 11 & rs 3821170 & $A D A M 23$ & $+432 \mathrm{C}>\mathrm{T}$ & 0.14 & 0.10 & 0.14 & 0.23 \\
\hline 12,13 & rs 72 & FGF3--[]--ANO1 & Int & 0.10 & 0.12 & 0.11 & 0.05 \\
\hline 12,13 & rs35213789 & AUTS2 & $260 \mathrm{C}>\mathrm{T}$ & 0.25 & 0.26 & 0.19 & 0.23 \\
\hline 12,13 & rs114947103 & CDHR3 & c. $1653+409 \mathrm{~T}>\mathrm{C}$ & 0.21 & 0.17 & 0.17 & 0.27 \\
\hline 12,13 & rs13281988 & NIPAL2--[]--KCNS2 & Intergenic & 0.31 & 0.29 & 0.33 & 0.32 \\
\hline 14 & rs10497394" & $C D C A 7--[]-S P 3$ & Intergenic & 0.23 & 0.26 & 0.34 & 0.12 \\
\hline 12,13 & rs67035515 & $B S N$ & c.225-5877_225-5874delTGAA & 0.86 & 0.83 & 0.89 & 0.87 \\
\hline 15 & rs $2932989^{c}$ & FNDCl & $\sim 6 \mathrm{~kb}$ from 3 'UTR & 0.88 & 0.87 & 0.91 & 0.87 \\
\hline 12,13 & rs73015965 & $P L G$ & c.112A>G (p.Lys38Glu) & 0.003 & 0.005 & 0.003 & 0.001 \\
\hline 12 & rs151208372 & DCBLD2--[]--COL8A1 & Intergenic & 0.09 & 0.08 & 0.15 & 0.13 \\
\hline
\end{tabular}

Abbreviations: Ref, reference; MAF, minor allele frequencies from gnomAD database; NFE, non-Finnish European; Lat, Latino, Afr, African.

${ }^{\mathrm{a}} p<5 \times 10^{-8}$; Variants are listed in order of increasing $p$-value.

bRefSeq accession numbers for coding and intronic variants: TMPRSS15, NM_002772.2; FUT2, NM_000511.5; TBX1, NM_005992.1; ABO, NM_020469.2; EFEMP1, NM_001039348.2; ADAM23, NM_003812.3; AUTS2, NM_015570.3; CDHR3, NM_152750.4; BSN, NM_003458.3; PLG, NM_000301.3.

${ }^{c}$ Only these variants/genes have been replicated in human subjects with otitis media using an independent dataset.

${ }^{\mathrm{d}}$ This variant was associated with childhood ear infections in the initial GWAS; however reanalysis with conditioning for the HLA-DRB1 Gln96 allele resulted in loss of association with the rs4329147 variant. 
Table 2. Single-tissue expression quantitative trait loci (eQTL) in the Genotype-Tissue Expression (GTEx) database among genome-wide significant loci for otitis media

\begin{tabular}{|c|c|c|c|}
\hline $\begin{array}{l}\text { Variant } \\
\text { (Chromosomal Band) }\end{array}$ & Gene & Tissue & $\begin{array}{r}e Q T L \\
\text { p-value }\end{array}$ \\
\hline \multirow[t]{14}{*}{ rs681343 (19q13.33) } & \multirow[t]{6}{*}{ FUT2 } & Esophageal mucosa & $1.4 \times 10^{-102}$ \\
\hline & & Unexposed skin & $5.0 \times 10^{-30}$ \\
\hline & & Exposed skin & $1.5 \times 10^{-25}$ \\
\hline & & Transverse colon & $2.7 \times 10^{-15}$ \\
\hline & & Small intestine (ileum) & $2.9 \times 10^{-10}$ \\
\hline & & Lung & $7.4 \times 10^{-06}$ \\
\hline & \multirow[t]{2}{*}{ NTN5 } & Transverse colon & $2.7 \times 10^{-15}$ \\
\hline & & Unexposed skin & $2.0 \times 10^{-13}$ \\
\hline & \multirow[t]{4}{*}{$R A S I P 1$} & Esophageal mucosa & $4.6 \times 10^{-16}$ \\
\hline & & Exposed skin & $4.9 \times 10^{-14}$ \\
\hline & & Unexposed skin & $3.1 \times 10^{-10}$ \\
\hline & & Sigmoid colon & $2.0 \times 10^{-07}$ \\
\hline & IZUMOI & Lung & $1.2 \times 10^{-06}$ \\
\hline & FAM $83 E$ & Exposed skin & $3.8 \times 10^{-06}$ \\
\hline rs1978060 (22q11.21) & $T B X 1$ & Prostate $^{b}$ & $5.2 \times 10^{-12}$ \\
\hline rs2808290 (10p12.1) & PTCHD3 & Testis $^{\mathrm{b}}$ & $9.7 \times 10^{-06}$ \\
\hline \multirow[t]{31}{*}{ rs4329147 (6p21.32) } & \multirow[t]{9}{*}{$H L A-D R B 5$} & Lung & $6.4 \times 10^{-86}$ \\
\hline & & Exposed skin & $7.0 \times 10^{-76}$ \\
\hline & & Esophageal mucosa & $3.8 \times 10^{-73}$ \\
\hline & & Unexposed skin & $1.2 \times 10^{-64}$ \\
\hline & & Stomach & $5.8 \times 10^{-43}$ \\
\hline & & Sigmoid colon & $2.6 \times 10^{-33}$ \\
\hline & & Vagina & $1.1 \times 10^{-21}$ \\
\hline & & Uterus & $1.8 \times 10^{-19}$ \\
\hline & & Small intestine (ileum) & $2.3 \times 10^{-18}$ \\
\hline & \multirow[t]{10}{*}{$H L A-D R B 6$} & Exposed skin & $2.6 \times 10^{-45}$ \\
\hline & & Lung & $2.8 \times 10^{-42}$ \\
\hline & & Esophageal mucosa & $3.7 \times 10^{-39}$ \\
\hline & & Unexposed skin & $3.5 \times 10^{-32}$ \\
\hline & & Transverse colon & $6.8 \times 10^{-28}$ \\
\hline & & Stomach & $6.0 \times 10^{-27}$ \\
\hline & & Small intestine (ileum) & $9.9 \times 10^{-16}$ \\
\hline & & Sigmoid colon & $4.8 \times 10^{-15}$ \\
\hline & & Uterus & $1.2 \times 10^{-10}$ \\
\hline & & Vagina & $3.2 \times 10^{-10}$ \\
\hline & \multirow[t]{7}{*}{$H L A-D Q B 1$} & Lung & $1.2 \times 10^{-22}$ \\
\hline & & Esophageal mucosa & $1.1 \times 10^{-20}$ \\
\hline & & Exposed skin & $7.2 \times 10^{-20}$ \\
\hline & & Stomach & $6.5 \times 10^{-15}$ \\
\hline & & Transverse colon & $4.9 \times 10^{-13}$ \\
\hline & & Sigmoid colon & $2.0 \times 10^{-11}$ \\
\hline & & Small intestine (ileum) & $8.8 \times 10^{-07}$ \\
\hline & \multirow[t]{5}{*}{$H L A-D R B 9$} & Lung & $1.0 \times 10^{-18}$ \\
\hline & & Small intestine (ileum) & $9.1 \times 10^{-10}$ \\
\hline & & Unexposed skin & $1.6 \times 10^{-08}$ \\
\hline & & Vagina & $1.3 \times 10^{-05}$ \\
\hline & & Exposed skin & $3.1 \times 10^{-05}$ \\
\hline
\end{tabular}




\begin{tabular}{|c|c|c|c|}
\hline & $H L A-D R B 1$ & Lung & $9.6 \times 10^{-14}$ \\
\hline & & Exposed skin & $1.9 \times 10^{-12}$ \\
\hline & & Esophageal mucosa & $2.2 \times 10^{-09}$ \\
\hline & & Unexposed skin & $2.9 \times 10^{-07}$ \\
\hline & & Transverse colon & $2.4 \times 10^{-05}$ \\
\hline & $H L A-D Q A 2$ & Esophageal mucosa & $2.4 \times 10^{-13}$ \\
\hline & & Lung & $5.7 \times 10^{-12}$ \\
\hline & & Exposed skin & $5.0 \times 10^{-11}$ \\
\hline & & Transverse colon & $1.1 \times 10^{-09}$ \\
\hline & & Sigmoid colon & $2.8 \times 10^{-06}$ \\
\hline & & Unexposed skin & $4.8 \times 10^{-06}$ \\
\hline & & Stomach & $5.5 \times 10^{-06}$ \\
\hline & PRRT1 & Esophageal mucosa & $6.1 \times 10^{-11}$ \\
\hline & & Exposed skin & $2.8 \times 10^{-06}$ \\
\hline & & Transverse colon & $2.1 \times 10^{-05}$ \\
\hline & $H L A-D Q B 2$ & Lung & $5.1 \times 10^{-10}$ \\
\hline & & Transverse colon & $4.4 \times 10^{-09}$ \\
\hline & & Sigmoid colon & $4.8 \times 10^{-07}$ \\
\hline & & Stomach & $1.8 \times 10^{-06}$ \\
\hline & $H L A-D Q A 1$ & Lung & $2.8 \times 10^{-09}$ \\
\hline & & Exposed skin & $7.3 \times 10^{-06}$ \\
\hline & & Esophageal mucosa & $2.5 \times 10^{-05}$ \\
\hline & NOTCH4 & Unexposed skin & $3.1 \times 10^{-09}$ \\
\hline & $C Y P 21 A 2$ & Exposed skin & $4.3 \times 10^{-05}$ \\
\hline & & Unexposed skin & $6.6 \times 10^{-05}$ \\
\hline & $C 4 A$ & Exposed skin & $5.1 \times 10^{-05}$ \\
\hline rs8176643 (9q34.2) & $A B O$ & Esophageal mucosa & $1.2 \times 10^{-06}$ \\
\hline & SURF1 & Exposed skin & $2.4 \times 10^{-06}$ \\
\hline & & Transverse colon & $2.8 \times 10^{-06}$ \\
\hline & & Lung & $1.1 \times 10^{-05}$ \\
\hline rs1802575 (2p16.1) & EFEMP1 & Unexposed skin & $8.0 \times 10^{-07}$ \\
\hline & & Exposed skin & $2.0 \times 10^{-06}$ \\
\hline rs885932 (6p22.1) & ZFP57 & Exposed skin & $6.0 \times 10^{-35}$ \\
\hline & & Esophageal mucosa & $1.6 \times 10^{-32}$ \\
\hline & & Lung & $1.4 \times 10^{-29}$ \\
\hline & & Unexposed skin & $1.2 \times 10^{-28}$ \\
\hline & & Transverse colon & $4.0 \times 10^{-24}$ \\
\hline & & Small intestine (ileum) & $5.7 \times 10^{-13}$ \\
\hline & & Sigmoid colon & $5.7 \times 10^{-11}$ \\
\hline & & Vagina & $2.4 \times 10^{-08}$ \\
\hline & $H L A-K$ & Unexposed skin & $2.4 \times 10^{-15}$ \\
\hline & & Transverse colon & $3.0 \times 10^{-13}$ \\
\hline & & Esophageal mucosa & $6.4 \times 10^{-13}$ \\
\hline & & Lung & $5.0 \times 10^{-12}$ \\
\hline & & Small intestine (ileum) & $2.0 \times 10^{-06}$ \\
\hline & & Sigmoid colon & $1.1 \times 10^{-05}$ \\
\hline & $H L A-A$ & Exposed skin & $1.4 \times 10^{-13}$ \\
\hline & & Unexposed skin & $3.4 \times 10^{-12}$ \\
\hline & & Esophageal mucosa & $6.0 \times 10^{-11}$ \\
\hline & TRIM31 & Unexposed skin & $8.2 \times 10^{-12}$ \\
\hline & & Lung & $1.1 \times 10^{-06}$ \\
\hline
\end{tabular}




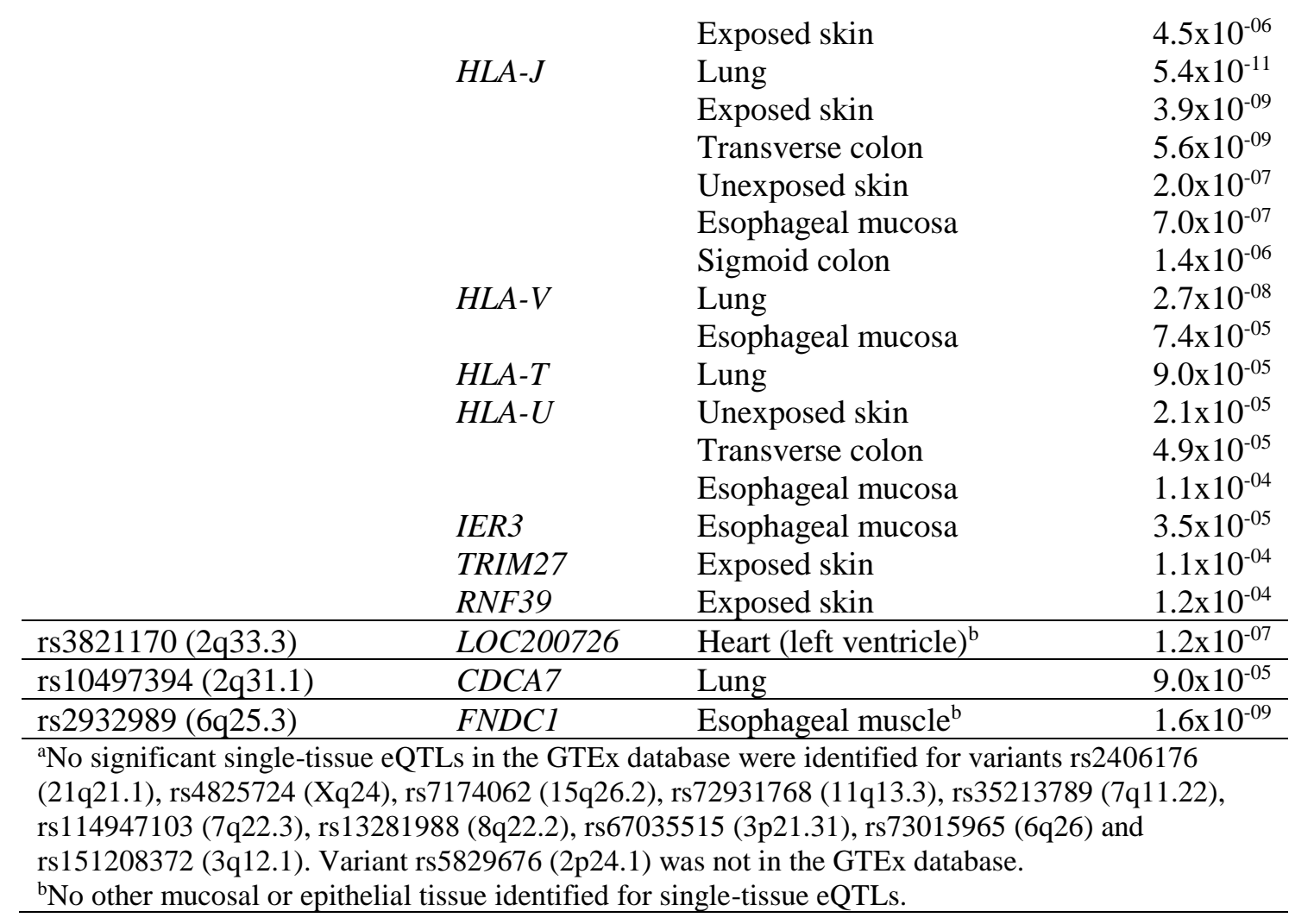


Table 3. Otitis media (OM)-related genes: animal studies 2014-2019

\begin{tabular}{|c|c|c|c|}
\hline Gene & Protein product & Known role in OM & Ref. \\
\hline Bpifal & Antibacterial & Deletion increases OM susceptibility & 30 \\
\hline Casp4 & Inflammasome effector & Inflammasome deficiency enhances OM & 31 \\
\hline Ccl3 & Chemotactic chemokine & Deletion enhances OM & 32 \\
\hline Ccr2 & Chemokine receptor & Deletion enhances OM & $\mathrm{U}$ \\
\hline$C d 44$ & $\begin{array}{l}\text { Hyaluronin receptor, } \\
\text { multifunctional }\end{array}$ & Deletion alters leukocyte recruitment in $\mathrm{OM}$ & 33 \\
\hline Celsrl & Intercellular organization & Mutation causes OM & $\mathrm{J}$ \\
\hline Corola & Lytic granule secretion & Mutation causes immunodeficiency and chronic OM & 34 \\
\hline Duspl & MAP kinase phosphatase & Inhibits MUC5AC production in response to NTHi & 35 \\
\hline Enppl & Transmembrane glycoprotein & Mutations cause OM with ectopic bone formation & 36 \\
\hline Entpdl & ATP hydrolase & Predicted to increase chronic OM & A \\
\hline Fbxoll & Transcription factor & Mutation causes a middle ear cavitation & 37 \\
\hline Flil & Transcription factor & Haploinsufficiency causes OM & 38 \\
\hline Grn & Granulin growth factor precursor & Deletion reduces bacterial clearance in $\mathrm{OM}$ & 39 \\
\hline Hbegf & Epithelial growth factor & Stimulates middle ear epithelial growth & 40 \\
\hline Illrn & IL1 receptor antagonist & Deletion exacerbates OM & $\mathrm{U}$ \\
\hline Mapk9 & $\mathrm{JNK}$ isoform 2 , gene regulation & JNK2 mutation exacerbates OM & 41 \\
\hline Mif & Pro-inflammatory mediator & Blocking MIF alleviates OM & 42 \\
\hline Mkpl & MAPK phosphatase & Upregulation reduces MUC5AB production in $\mathrm{OM}$ & 35 \\
\hline Ncf 2 & Superoxide source in neutrophils & Predicted to increase chronic OM & A \\
\hline Nfkbl & Immune, growth signaling & Deletion enhances OM & $\mathrm{U}$ \\
\hline Nisch & Cell signaling & Mutation causes OM & 43 \\
\hline Nlrp3 & Pathogen receptor, inflammasome & Inflammasome deficiency enhances OM & 31 \\
\hline Nodl & Pathogen receptor & Mutation exacerbates OM & $\mathrm{U}$ \\
\hline Nod2 & Pathogen receptor & Mutation reduces bacterial clearance in $\mathrm{OM}$ & 44 \\
\hline Pail & Plasminogen inhibitor & Deletion exacerbates OM & 45 \\
\hline $\operatorname{Pax} 9$ & Growth-related transcription factor & Down-regulation leads to OM & 46 \\
\hline Pycard & ASC inflammasome component & Deletion enhances OM & 31 \\
\hline Ripk2 & Pathogen receptor signaling & Deletion disables OM recovery & $\mathrm{U}$ \\
\hline Spag6 & Cilia gene & Deletion causes OM & 47 \\
\hline Tbxl & Transcription factor & Mutation alters facial morphology, increases OM incidence & 22 \\
\hline Tlr2 & Pathogen receptor & Deletion exacerbates OM & 48 \\
\hline
\end{tabular}

Abbreviations: U, unpublished observations from D.G. Hur, B. Nuyen and A. Kurabi; J, phenotype from Jackson

Labs; NTHi, non-typeable Haemophilus influenzae; A, ARCHS4 database 